\title{
Near-future climate change over Europe with focus on Croatia in an ensemble of regional climate model simulations
}

\author{
Čedo Branković* ${ }^{*}$ Mirta Patarčić, Ivan Güttler, Lidija Srnec \\ Croatian Meteorological and Hydrological Service (DHMZ), Grič 3, 10000 Zagreb, Croatia
}

\begin{abstract}
The RegCM climate model was used at a $35 \mathrm{~km}$ resolution to downscale the 3-member global ECHAM5/MPI-OM ensemble based on the IPCC A2 scenario covering the EuropeanMediterranean domain. Within the reference climate (1961-1990), the model high $2 \mathrm{~m}$ temperatures $(\mathrm{T} 2 \mathrm{~m})$ were reduced and low temperatures were increased relative to verification in a large portion of the domain. Precipitation was underestimated in summer over the Mediterranean region but was overestimated over western Europe in winter, probably due to excessive westerlies in the global model. When RegCM was forced by ERA-40, the dominant errors in the summer T2m appear to be genuine RegCM errors, but a large fraction of errors in winter precipitation was imported from the lateral boundaries. In the near future (2011-2040), the summer T2m is projected to increase by $+1.8^{\circ} \mathrm{C}$ over southwest Europe. The simulated change in precipitation is small and is significant only in regions around the Mediterranean. The wetter north and drier south, a major feature in projections of the European winter climate in the late 21st century, is not predicted for the near future. Similarly, summer drying is confined to western Europe in contrast to nearly continental scale drying observed in projections of the late 21st century. This finding may influence the approaches for adaptation to climate change in the first half and at the end of this century. The effects of downscaling at small scales are analysed for the case of Croatia. The spatial distribution of the number of days with extreme $\mathrm{T} 2 \mathrm{~m}$ and precipitation in RegCM is consistent with observations. However, this metric is generally underestimated, indicating that over complex orography, even higher horizontal resolution is needed to better resolve climate extremes.
\end{abstract}

KEY WORDS: RegCM - Systematic errors $\cdot$ Regional climate change $\cdot$ Ensemble integrations Europe $\cdot$ Croatia

\section{INTRODUCTION}

Dynamical downscaling or regional model nesting is a well-established technique used to represent climate change at regional scales (e.g. Rummukainen 2010). The horizontal resolution of coupled atmosphere-ocean general circulation models (AOGCMs), which are the basis for applications of climate change scenarios, is still too coarse to represent certain small-scale physical processes in detail, in particular those features that are associated with small-scale variations in orography. The results from the EU-funded PRUDENCE project (Prediction of regional scenarios and uncertainties for defining European climate change risks and effects), for example, demonstrate that there are advantages in using regional climate models (RCMs) in the assessments of climate change over Europe because they better resolve processes at regional scales (e.g. Déqué et al. 2005, Christensen et al. 2007a).

Most examinations of climate change using RCMs analyse time periods that are in the distant future relative to the reference climate. For example, Gao et al. 
(2006), Krichak et al. (2007), Tapiador \& Sanchez (2008), May (2008) and Lionello et al. (2008) examined time periods toward the end of the 21st century. The PRUDENCE project, which involved $>20$ European research groups, specifically focused on the years 2071-2100. Although the choice of the future period is somewhat arbitrary, one possible reason for a general 'neglect' of climate periods earlier in the 21st century may be a relatively low signal induced by greenhouse gases (GHGs) in the Intergovernmental Panel on Climate Change (IPCC) emission scenarios, even for those scenarios with high forcing (see, for example, Fig. 10.4 in Meehl et al. 2007). RCM studies of climate change in the first half of the 21st century do exist (e.g. Szépszó \& Horányi 2008, Diffenbaugh \& Ashfaq 2010, Kjellström et al. 2011), but there are relatively few of them. The experience at the Croatian Meteorological and Hydrological Service (DHMZ) is that long-term planning and the potential use of relevant data regarding adaptation to climate change in Croatia rarely concern periods beyond the middle of this century. Thus, for scientific and practical reasons, the present study focuses on climate change in the immediate future. Specifically, we analyse the downscaling results of the RegCM3 $\mathrm{RCM}$ (hereafter referred to as RegCM) driven by an ensemble of the ECHAM5/MPI-OM global climate model for $30 \mathrm{yr}$ during the 20th century and for $30 \mathrm{yr}$ in the near future.

Although RCM studies of climate change for Europe have been presented before (e.g. the PRUDENCE project), southern Europe and the Mediterranean region warrant special attention because they may experience non-negligible climate change in the 21st century (Giorgi 2006). In the present study, particular attention is given to 1 sub-region of the European/Mediterranean domain, namely, Croatia. We examine the effects (and the problems) of dynamical downscaling over this relatively small region with a complex orography and coastline.

The initial and lateral boundary conditions for dynamical downscaling were taken from the 3-member ensemble of the ECHAM5/MPI-OM (hereafter referred as EH5OM) global model integrated under the IPCC A2 scenario. The ensemble approach alleviates initial data uncertainties and, in terms of statistical significance and climate predictability, increases our confidence in the downscaled results. The 3-member RCM ensemble driven by the same AOGCM may appear too small when compared with multi-model RCM ensembles (e.g. Hewitt \& Griggs 2004, Déqué et al. 2005). The multi-model ensembles enable, through the probabilistic component, an estimate of robustness and uncertainty in the prediction (e.g. Palmer et al. 2005, Weigel et al. 2010). Based on these arguments, our single-model ensemble approach would have certain limitations and weaknesses, as has been emphasised in previous studies (e.g. Im et al. 2011, Mariotti et al. 2011). However, because the quality of individual models in the multi-model ensemble may vary considerably, a number of questions remain regarding, for example, how to construct, calibrate and evaluate multi-model ensembles (see the discussion in Knutti 2010 and references therein). In addition, running multi-model ensembles requires considerable technical and human resources, which are currently beyond the scope of the DHMZ. Thus, our study may be viewed as an attempt to assess simulated climate and climate change using a limited, 'low-order' ensemble. The choice of only a single AOGCM implies that our results and conclusions may not unconditionally extend to other models.

The output from the EH5OM global atmosphereocean model has been used for various climate downscaling studies (e.g. Hagemann et al. 2009, Endler \& Matzarakis 2010, Früh et al. 2010, Kjellström et al. 2011). According to the study by Reichler \& Kim (2008), EH5OM is one of the most successful CMIP3 1 global models in simulating the climate of the 20th century. This ranking was based on a metric calculated from the climatologies of 14 surface and upper-air variables in the period 1979-1999. Although the A2 scenario defines the upper bound of GHG concentrations and sulphate aerosols in the late 21st century, it was chosen because the multi-model mean of global surface warming (relative to 19801999) is projected to be approximately $1.2^{\circ} \mathrm{C}$ by 2040 compared to approximately $3.6^{\circ} \mathrm{C}$ in 2100 (Meehl et al. 2007).

RegCM systematic errors were first assessed by comparing simulations of a reference climate (19611990) with observational data. This step is important because the climate change signals in the near future can be weak and thus susceptible to the impact of modelling errors. By relating errors in a single model to projected climate change, one should be able to associate uncertainties for a given change with the deficiencies of that particular model. The errors in a regional model should preferably be viewed in the context of driving model errors, but, for brevity, such a comparison is excluded here. The reader is referred to van Ulden \& van Oldenborgh (2006) or to Branković et al. (2010) for the discussion of EH5OM sys-

\footnotetext{
${ }^{1}$ Coupled Model Intercomparison Project, Lawrence Livermoore National Laboratory, Livermore, CA, USA
} 
tematic biases over Europe. To ascertain to what extent biases in the RegCM simulations are influenced by the lateral boundaries, an additional downscaling simulation is performed, whereby RegCM is forced by 'perfect' boundary conditions, represented by the ERA-40 re-analysis data (Uppala et al. 2005).

We focus primarily on near-surface temperature (T2m) and precipitation, the 2 parameters that are largely influenced by small orographic scales. The seasonally averaged near-surface daily maximum (T2max) and daily minimum (T2min) temperatures are also examined to gain insight into their dependency on climate change. Certain other significant and extreme parameters on the regional scale are also analysed; in particular, a model simulation of the reference climate is compared with Croatia's station data.

We occasionally compare our results of near-future climate change with those in the late 21st century that are found to be common in most modelling studies. For example, climate change projections unanimously agree, irrespective of the model or scenario employed, that the magnitude of warming could be largest at the end of the 21st century. Therefore, we compare the temperature change in the near future with such a robust climate change signal. This type of analysis may appear to give limited results because such a comparison could involve different RCMs, different driving AOGCMs, different resolutions and different scenarios. However, even if such an approach is considered to have possible limitations, it helps to place the near-future climate change into a proper perspective.

In the next section, the regional model, the organisation of the experiments and the statistical methods are described. In Section 3, systematic model errors in the climate mean and interannual variability are examined. Section 4 analyses the near-future climate and the variability thereof in comparison with the reference climate. In Section 5, we focus on the regional scale: first, model results are compared with station data and, next, changes of certain extreme and significant parameters in the near future are examined. Section 6 contains a summary and concluding remarks.

\section{EXPERIMENTS AND METHODS}

\subsection{Model and experiments}

The RegCM was used to dynamically downscale the 3-member ensemble simulations made by the EH5OM AOGCM. The integration domain is centred at $45^{\circ} \mathrm{N}, 8.5^{\circ} \mathrm{E}$ and covers most of Europe and the Mediterranean region with regular $35 \mathrm{~km}$ grid spacing (Fig. 1b). The largest orographic difference between the EH5OM and the RegCM simulations is located in the Alpine region and is approximately $1000 \mathrm{~m}$. Over Croatia, the difference between the 2 models amounts to $>500 \mathrm{~m}$ at the westernmost portion of the Croatian Adriatic coast (Fig. 1c). In the vertical, there were 23 levels, with the model top located at $100 \mathrm{hPa}$. Atmospheric variables and seasurface temperatures defining both the initial conditions and lateral boundaries, updated in $6 \mathrm{~h}$ intervals, were taken from the EH5OM simulations. The details of the RegCM are given in Pal et al. (2007). For our integrations, the following physical parameterisations were included: planetary boundary layer (Holtslag et al. 1990), convective precipitation scheme (Grell 1993) with the Arakawa-Schubert closure (Arakawa \& Schubert 1974), a large-scale precipitation scheme (Pal et al. 2000), the Biosphere-Atmosphere Transfer Scheme (BATS) land surface scheme (Dickinson et al. 1993) and the radiative transfer algorithm from the NCAR CCM3 (Kiehl et al. 1996).

The input for downscaling was obtained from the CERA $^{2}$ archive. The EH5OM is an AOGCM consisting of the atmospheric model ECHAM5 and the oceanic model MPI-OM. In this experiment, ECHAM5 was run at the T63L31 spectral resolution (Roeckner et al. 2003, 2006), which corresponds to $1.875^{\circ}$ or approximately $200 \mathrm{~km}$. The MPI-OM is the global ocean general circulation model with a horizontal resolution of $1.5^{\circ}$ and 40 vertical levels (Marsland et al. 2003). The frequency of coupling between the atmospheric and oceanic models is performed daily with no flux adjustment (Jungclaus et al. 2006).

Downscaling was performed for two $30 \mathrm{yr}$ periods: the reference climate (1961-1990, denoted as P0) and the future climate (2011-2040, P1). For P0, the concentrations of the GHGs in EH5OM were specified at the observed values; for future climate, the time evolution of the GHGs was based on the IPCC A2 scenario (Nakićenović et al. 2000). By 2040, the $\mathrm{CO}_{2}$ concentration was 481 ppmv (compared to 352 ppmv in 1990), the $\mathrm{CH}_{4}$ concentration was 2357 ppbv (1694 ppbv in 1990) and the $\mathrm{N}_{2} \mathrm{O}$ concentration was 360 ppbv (308 ppbv in 1990). Each EH5OM ensemble member was initiated from the pre-industrial control experiment and integrated to the year 2100. Time evolution of radiative forcing in the RegCM was per-

\footnotetext{
${ }^{2}$ Climate and Environmental Retrieving and Archive, World Data Center for Climate, Hamburg, Germany (http://cerawww.dkrz.de/WDCC/ui/Index.jsp)
} 

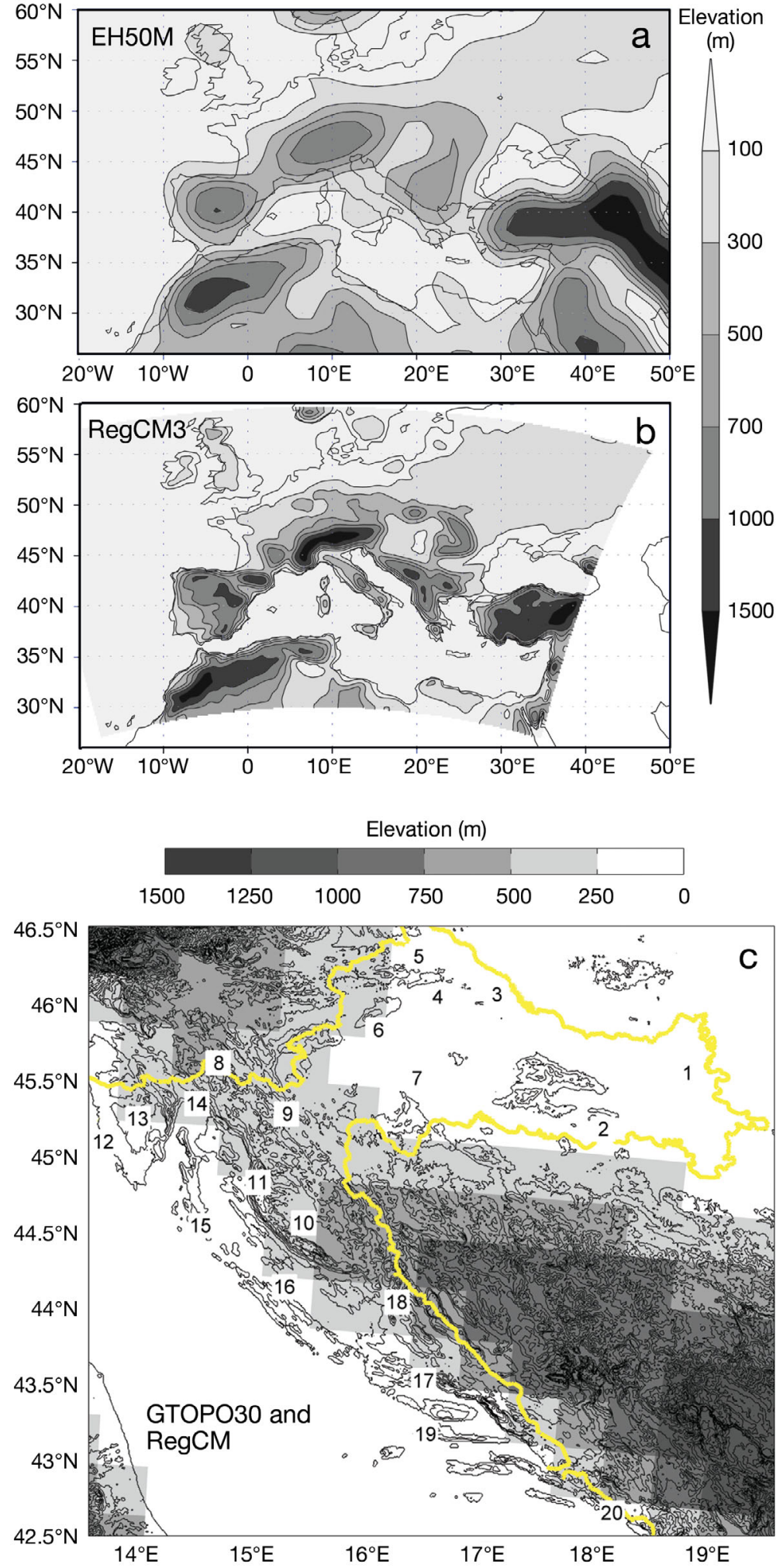

Fig. 1. Orography in (a) EH5OM and (b) RegCM over Europe and (c) over Croatia. In Panel c high resolution contours are superimposed on RegCM grid boxes. Contours (a,b) 100, 300, 500, 700, 1000 and 1500 m, (c) every $250 \mathrm{~m}$. Stations described in Table 1 are indicated by numbers in white squares in Panel c. The yellow contour represents the boundary of Croatia formed in a similar manner as it was in the driving global model: for the 20th century climate, the observed concentrations of the GHGs $\left(\mathrm{CO}_{2}, \mathrm{CH}_{4}, \mathrm{~N}_{2} \mathrm{O}\right.$, chlorofluorocarbons [CFCs]) are prescribed, and future climate concentrations are defined according to the IPCC A2 scenario. No aerosols were included in RegCM integrations. For P0, an additional downscaling experiment (at the same $35 \mathrm{~km}$ resolution) was performed in which the regional model was forced by ERA-40 data. Assuming that re-analysis represents 'perfect' boundary forcing, this experiment, hereafter denoted as RegCM (ERA40), enables the discrimination of genuine $\mathrm{RegCM}$ bias from bias imported via the lateral boundaries when RegCM is forced by a global model.

\subsection{Verification data}

For the verification of the T2m, T2max, T2min and precipitation data for the reference climate, CRU ${ }^{3}$ (TS 2.1 data set, www. cru.uea.ac.uk/ timm/grid/CRU_TS_2_1.html) data were used (New et al. 2002, Mitchell \& Jones 2005), where T2max and T2min are defined as seasonal means of daily maximum and daily minimum temperatures, respectively. Because CRU data are derived from land stations, verification of the RegCM reference climate (and also of the EH5OM reference climate) is made on the CRU grid $\left(0.5^{\circ} \times 0.5^{\circ}\right.$ latitude/longitude $)$ over land points only. We also compared our $\mathrm{T} 2 \mathrm{~m}$ and precipitation data with the EOBS ${ }^{4}$ dataset (Klein Tank et al. 2002, Haylock et al. 2008), which is available for the same grid as the CRU data. As is the case for CRU, the EOBS data are defined over land points only. Possible errors in the observations make it beneficial to compare the modelling results against multiple verification datasets. For example, Giorgi at al. (2004a) found that when compared with certain other datasets, the CRU precipitation data may underestimate observed val-

\footnotetext{
${ }^{3}$ Climate Research Unit, School of Environmental Sciences, University of East Anglia, Norwich, UK Part of the European Climate Assessment (ECA) project (http://eca.knmi.nl/)
} 
Table 1. Stations in Croatia (Fig. 1c) and the corresponding heights in RegCM and EH5OM

\begin{tabular}{|llcrrrr|}
\hline No. Station & $\begin{array}{c}\text { Latitude } \\
(\mathrm{N})\end{array}$ & $\begin{array}{r}\text { Longitude } \\
(\mathrm{E})\end{array}$ & $\begin{array}{r}\text { Altitude } \\
(\mathrm{m})\end{array}$ & $\begin{array}{r}\text { RegCM } \\
\text { height }(\mathrm{m})\end{array}$ & $\begin{array}{r}\text { EH5OM } \\
\text { height }(\mathrm{m})\end{array}$ \\
\hline 1 & Osijek & $45^{\circ} 32^{\prime}$ & $18^{\circ} 44^{\prime}$ & 89 & 113 & 174 \\
2 & Slavonski Brod & $45^{\circ} 10^{\prime}$ & $18^{\circ} 00^{\prime}$ & 88 & 180 & 174 \\
3 & Đurđevac & $46^{\circ} 03^{\prime}$ & $17^{\circ} 04^{\prime}$ & 121 & 155 & 254 \\
4 & Križevci & $46^{\circ} 02^{\prime}$ & $16^{\circ} 33^{\prime}$ & 155 & 182 & 254 \\
5 & Varaždin & $46^{\circ} 18^{\prime}$ & $16^{\circ} 23^{\prime}$ & 167 & 206 & 254 \\
6 & Zagreb Maksimir & $45^{\circ} 49^{\prime}$ & $16^{\circ} 02^{\prime}$ & 123 & 250 & 254 \\
7 & Sisak & $45^{\circ} 30^{\prime}$ & $16^{\circ} 22^{\prime}$ & 98 & 176 & 254 \\
8 & Parg & $45^{\circ} 36^{\prime}$ & $14^{\circ} 38^{\prime}$ & 863 & 545 & 421 \\
9 & Ogulin & $45^{\circ} 16^{\prime}$ & $15^{\circ} 14^{\prime}$ & 328 & 407 & 421 \\
10 & Gospić & $44^{\circ} 33^{\prime}$ & $15^{\circ} 23^{\prime}$ & 564 & 440 & 237 \\
11 & Zavižan & $44^{\circ} 49^{\prime}$ & $14^{\circ} 59^{\prime}$ & 1594 & 0 & 421 \\
12 & Rovinj & $45^{\circ} 05^{\prime}$ & $13^{\circ} 38^{\prime}$ & 20 & 0 & 599 \\
13 & Pazin & $45^{\circ} 14^{\prime}$ & $13^{\circ} 56^{\prime}$ & 291 & 262 & 599 \\
14 & Rijeka & $45^{\circ} 20^{\prime}$ & $14^{\circ} 27^{\prime}$ & 120 & 373 & 421 \\
15 & Mali Lošinj & $44^{\circ} 32^{\prime}$ & $14^{\circ} 29^{\prime}$ & 53 & 0 & 237 \\
16 & Zadar & $44^{\circ} 08^{\prime}$ & $15^{\circ} 13^{\prime}$ & 5 & 0 & 237 \\
17 & Split Marjan & $43^{\circ} 31^{\prime}$ & $16^{\circ} 26^{\prime}$ & 122 & 425 & 310 \\
18 & Knin & $44^{\circ} 02^{\prime}$ & $16^{\circ} 12^{\prime}$ & 234 & 500 & 310 \\
19 & Hvar & $43^{\circ} 10^{\prime}$ & $16^{\circ} 27^{\prime}$ & 20 & 0 & 310 \\
20 & Dubrovnik & $42^{\circ} 39^{\prime}$ & $18^{\circ} 05^{\prime}$ & 52 & 0 & 515 \\
\hline
\end{tabular}

not different, is considered for the $95 \%$ confidence level. The use of statistical significance is, to a certain extent, conditioned by the dependence of RegCM on the EH5OM forcing data.

Interannual variability is discussed in terms of empirical orthogonal functions (EOFs; see e.g. von Storch \& Zwiers 1999 for a description of EOFs). The EOFs are computed from modelled and observed anomalies over the entire regional model domain on the CRU grid for land points only. We focus on the EOF dominant modes that uniquely describe the model's ability to represent interannual variability (Zhu \& Liang 2007). For the calculation of spatial correlation coefficients between EOF patterns, weighting by grid-box area was performed. To assess the significance of spatial similarities between the modelled and observed EOFs

ues by a non-negligible margin. In the following sections, only major differences, if any, between CRU and EOBS verifications are discussed.

For Croatia, the RegCM climatology was compared with observational data from 20 selected stations. These stations are listed in Table 1, and their locations are indicated in Fig. 1c. The basic climatological features for the stations considered are given in Zaninovi et al. (2008). The largest orographic difference between RegCM and station data (>1500 $\mathrm{m}$ ) is for the Zavižan station (Stn 11; Table 1 and Fig. 1c), which is located on Velebit Mountain near the Adriatic Sea (cf. Fig. 1c). No temperature adjustment was made for the height differences between various datasets.

\subsection{Statistical methods}

For calendar seasons December-January-February (DJF), March-April-May (MAM), June-July-August (JJA) and September-October-November (SON), ensemble averages were constructed and analysed. The statistical significance of the differences between the modelled and verification averages (and of the differences between the reference and future climates) was estimated by the standard 2-tailed Student's $t$-test. In either case, the variance of the 2 datasets was assumed to be similar. The null hypothesis, i.e. that the means of the 2 samples are (and between the 2 models), a bootstrapping method (e.g. Press et al. 1995) was applied. This allowed the computation of percentiles and confidence intervals for spatial correlation coefficients.

\section{VERIFICATION OF SURFACE FIELDS}

Deficiencies in the accuracy of simulations of the current climate for a given region may lead to uncertainties in estimating future climate change (Krichak et al. 2007). Such uncertainties, expressed in terms of model systematic errors, may affect our confidence in climate change projections. This confidence is increased if the ratio between the magnitude of the model climate response and its systematic errors is large (Déqué et al. 2005). Therefore, we analysed errors first in RegCM for simulated climate mean and variability. An attempt to relate these errors with the effects of climate change is made in Section 4.

\subsection{Near-surface temperature (T2m)}

For T2m, the largest negative errors in the ensemble mean of the RegCM seasonal climate occur in JJA (Fig. 2c). The area encompassed by the $-2^{\circ} \mathrm{C}$ contour in Fig. 2c, particularly over northeastern Europe, is marginally larger than in the verification 


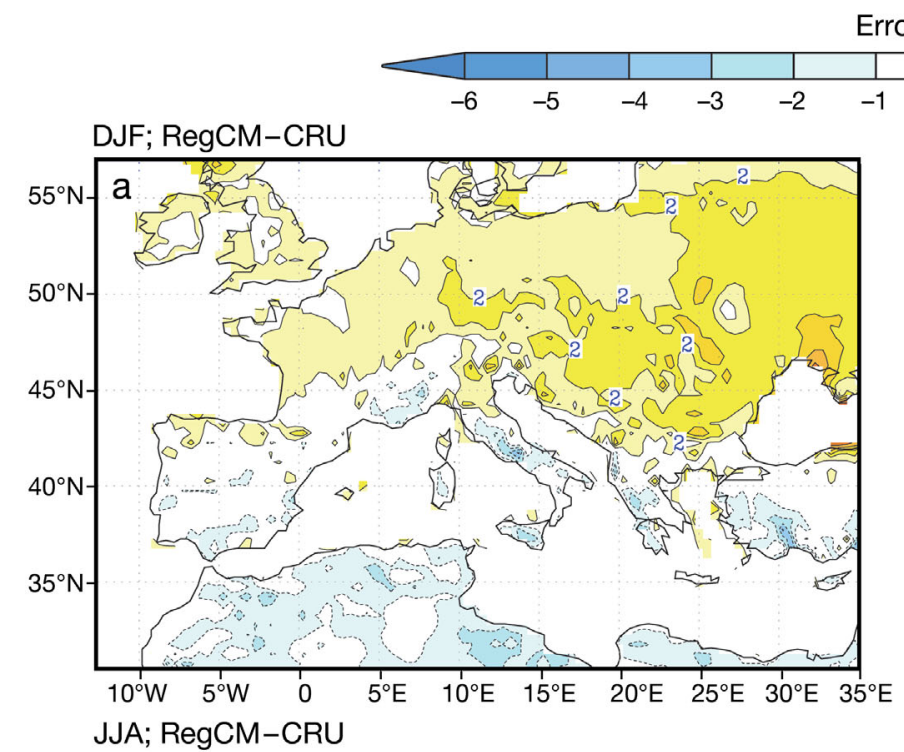

Error $\left({ }^{\circ} \mathrm{C}\right)$

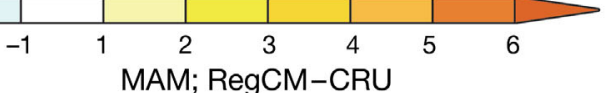
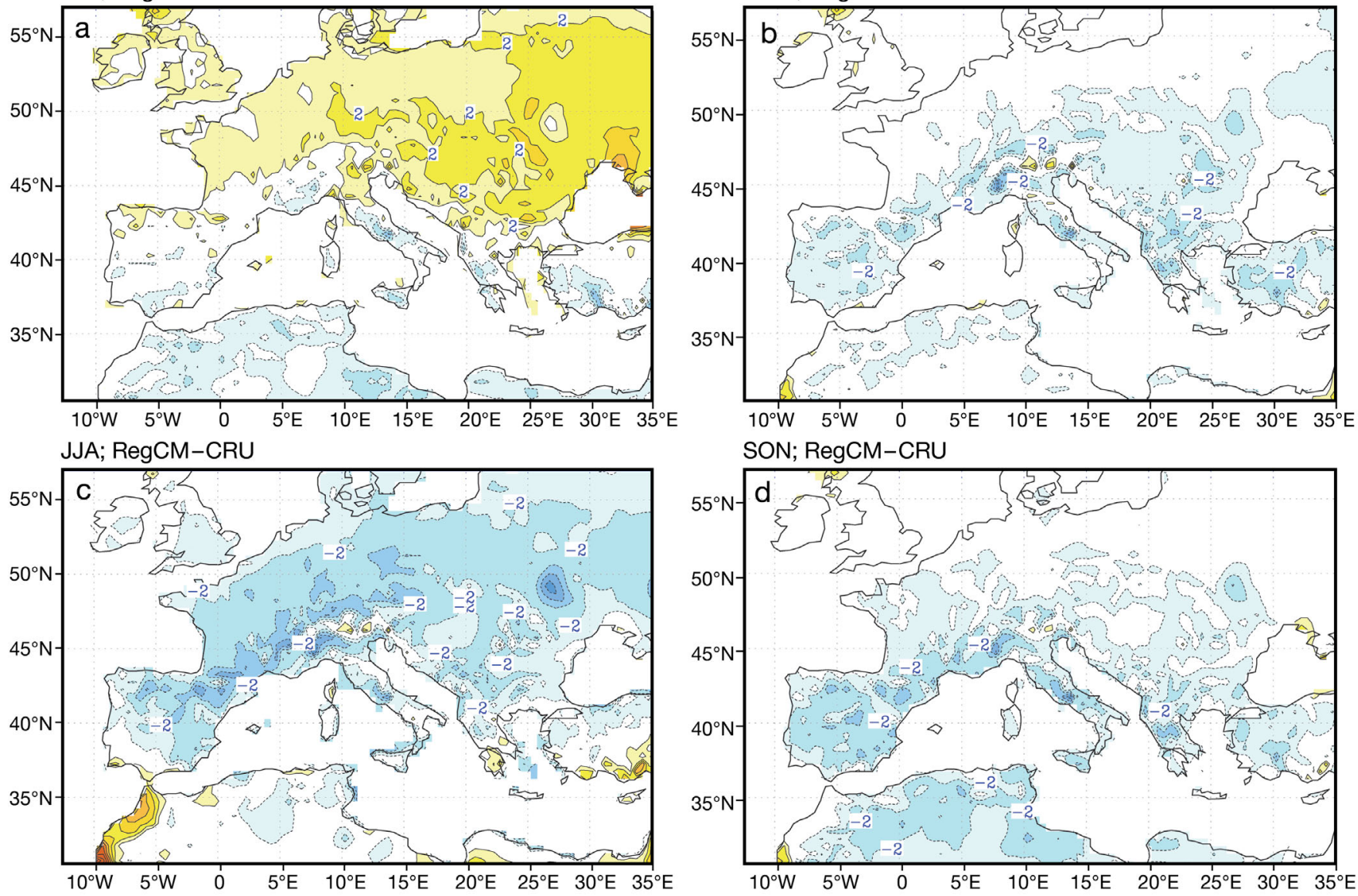

DJF; RegCM(ERA40)-CRU
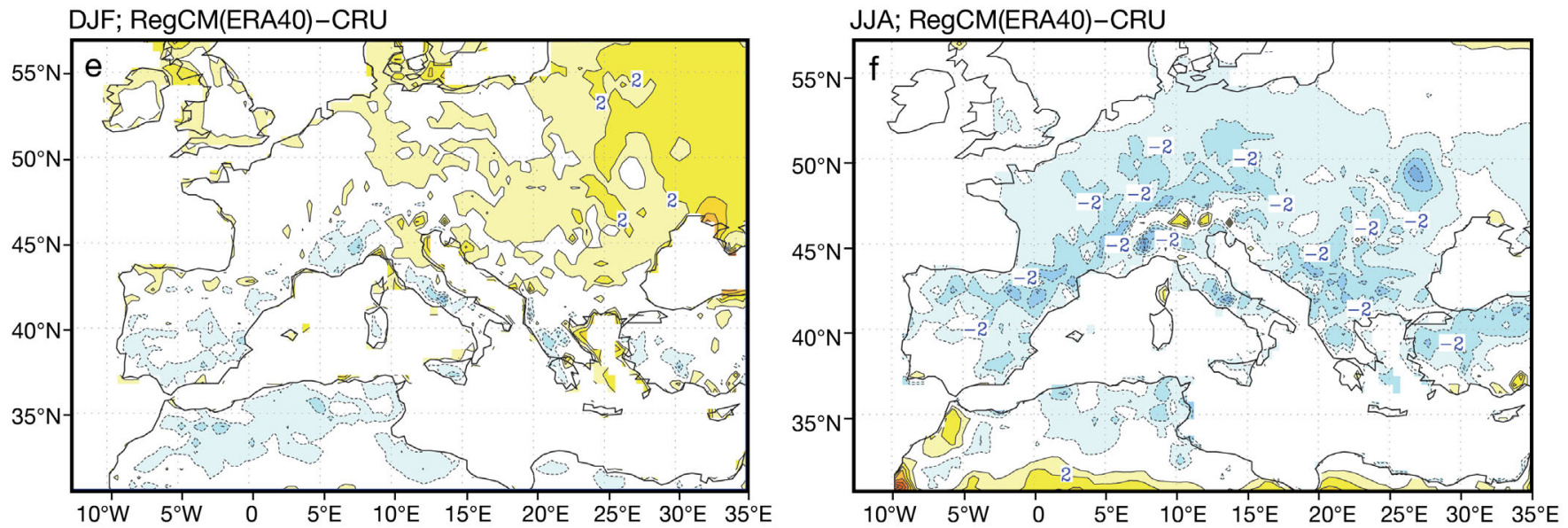

Fig. 2. RegCM near-surface temperature (T2m) errors with respect to CRU (RegCM-CRU) in the period 1961-1990 for ensemble seasonal means in (a) December-January-February (DJF), (b) March-April-May (MAM), (c) June-July-August (JJA) and (d) September-October-November (SON) and RegCM(ERA40) T2m errors with respect to CRU in (e) DJF and (f) JJA.

Contours every $\pm 1^{\circ} \mathrm{C}$

with the EOBS data (not shown). Over the major mountain ranges, the differences between the 2 verifications are rather patchy and incoherent and rarely exceed $0.5^{\circ} \mathrm{C}$. In RegCM(ERA40), somewhat weaker negative errors are dominant (Fig. 2f), indicating a genuine summer RegCM cold bias of -1 to $-2^{\circ} \mathrm{C}$ over 
most of Europe, and more than $-3^{\circ} \mathrm{C}$ in certain locations. In MAM and SON (Fig. 2b,d), a predominant cold bias is also observed; however, this bias is smaller than that observed in JJA and is primarily confined to the area south of $50^{\circ} \mathrm{N}$. The MAM cold bias in RegCM(ERA40) changes little when compared with the total bias depicted in Fig. 2b, implying that a genuine RegCM bias also prevails in this season. In SON, the cold bias from RegCM(ERA40) is comparably weaker, and thus a larger fraction of the bias may be attributed to external forcing. In DJF, a warm bias prevails in the northern portion of the domain and a weak cold bias in the southern portion (Fig. 2a). The errors depicted in Fig. 2 are statistically significant at the $95 \%$ confidence level over much of the integration domain. A significant portion of the winter warm bias over eastern Europe may be explained as authentic RegCM bias (Fig. 2e). Over western and central Europe, the global model contributes to RegCM bias relatively strongly. Our results broadly agree with those by Noguer et al. (1998), who found for their RCM that the winter temperature (and precipitation) errors were primarily imported via the lateral boundaries. In the summer, when the lateral advection is weak, these errors were influenced by both global model boundaries and regional model physics.

The cold bias depicted in Fig. 2 is even more pronounced for T2max (not shown), particularly in JJA, when the bias exceeds $-5^{\circ} \mathrm{C}$ in a large portion of the domain. The T2max warm bias in DJF, however, has a somewhat reduced amplitude relative to that shown in Fig. 2a. The largest fraction of the T2max cold bias in JJA and MAM is, similar to T2m, due to the inherent RegCM error, whereas the contribution of the imported bias is increased in DJF and SON. The errors in T2min (not shown) are similar to those depicted in Fig. 2, but generally have a smaller amplitude. The exception is the warm bias in DJF, which becomes relatively strong (reaching $+5^{\circ} \mathrm{C}$ over eastern Europe), with the authentic RegCM error being dominant. Thus, the amplitude of high temperatures in RegCM is generally smaller when compared with observations (cold bias), particularly in summer, when all temperatures (T2m, T2min, T2max) are at their highest in the annual cycle. In winter, RegCM tends to increase low temperatures (warm bias), primarily in the east and northeast, which are the coldest regions of the domain. Generally, a larger fraction of the near-surface temperature biases are due to inherent RegCM errors, and a smaller portion is caused by external forcing from the EH5OM, which principally introduces errors in the colder period of the year.
The ability of the regional model to simulate the observed $\mathrm{T} 2 \mathrm{~m}$ interannual variability was assessed by comparing the modelled and CRU EOF patterns. In DJF, the largest loadings in CRU EOF1 (Fig. 3a) in the northeastern portion of the domain represent the strongest impact of snow cover on $\mathrm{T} 2 \mathrm{~m}$ variations. Although the model underestimates the observed variability, it reproduces the northeast-to-southwest orientation of the EOF1 pattern reasonably well (Fig. 3c). The location of maximum variability, however, is shifted toward the northeastern corner of the domain. Park et al. (2008) also reported a successful RegCM simulation of T2m interannual variability, as defined by EOFs for eastern Asia. The spatial correlation between the regional model EOF1 and the CRU data is relatively high for the winter $(0.93$; Table 2). It should be noted that to facilitate comparisons, the sign of some EOFs in Fig. 3 (and also in Fig. 5) was multiplied by -1 . The correlation between the observed and modelled T2m for EOF2 and EOF3 drops dramatically when compared with EOF1. However, the correlation remains quite strong between the global and regional models for the first 3 EOFs (0.99, 0.92 and 0.91, respectively). These relatively strong correlations are indicative of the fact that interannual variations in RegCM are governed primarily by boundary conditions. For all coefficients, the bootstrapping method yields confidence intervals that do not exceed 0.1 at the $90 \%$ confidence level, indicating a relatively high degree of robustness of the spatial correlation coefficients.

The spatial variation of the winter EOF1 in RegCM(ERA40) (Fig. 3e) appears more similar to the variation observed in the CRU data (Fig. 3a) than to the variation seen in the RegCM ensemble (Fig. 3c). Although the maximum loading in the northeast is weaker than in Fig. 3a, the orientation of the RegCM(ERA40) pattern is better captured than the pattern orientation shown in Fig. 3c. The better representation of the patterns of interannual variation in the regional model during winter, when 'perfect' boundary conditions are used, is further confirmed by correlation coefficients for the first 3 EOFs between RegCM(ERA40) and CRU, which are the highest for all models (Table 2). The deterioration in the representation of the pattern of interannual variation from RegCM(ERA40) to the RegCM ensemble may be related to features of the corresponding mean states, which are represented here by their respective systematic errors. When the magnitude (and the spatial extent) of systematic errors is relatively small (as when RegCM is driven by ERA-40), the model represents the pattern of 


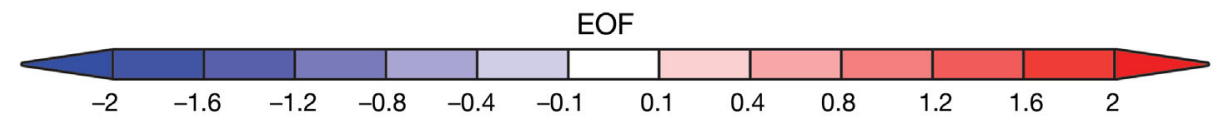

DJF; CRU; (63.96\%)

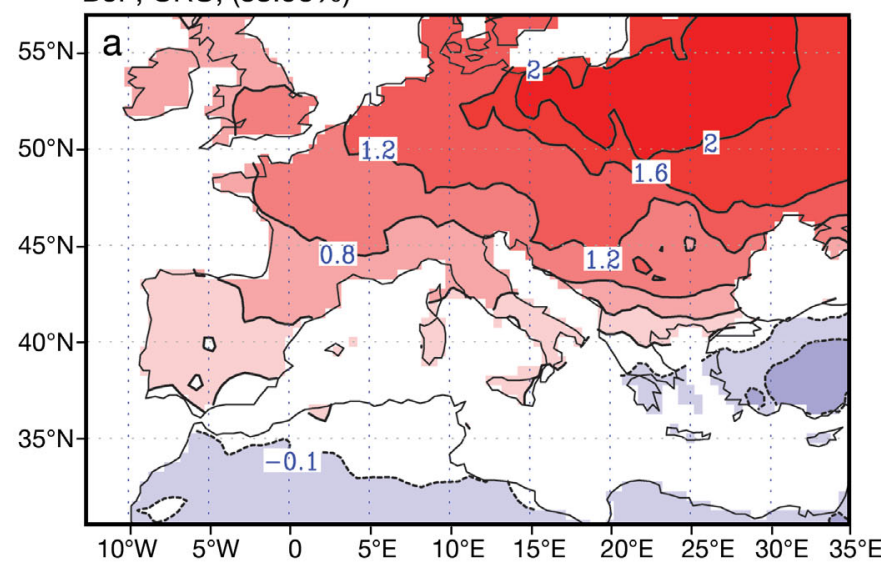

DJF; RegCM; (51.28\%)

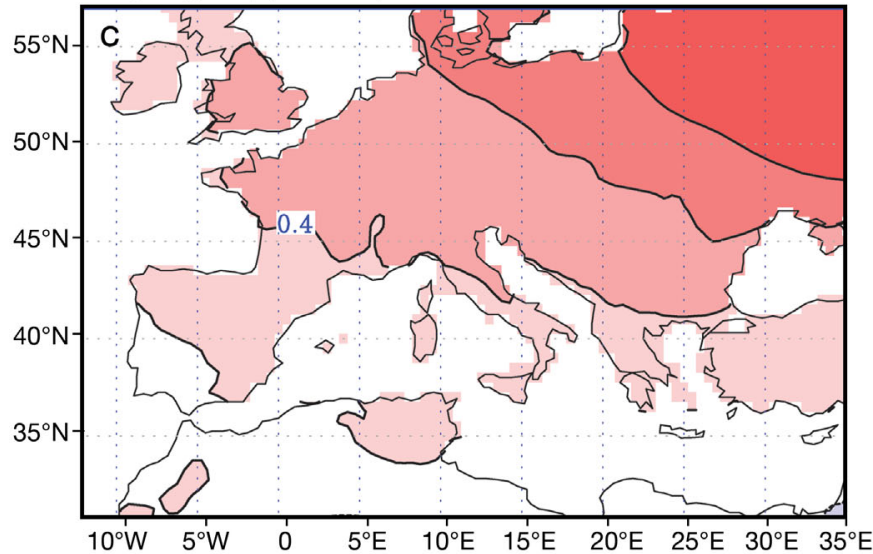

DJF; RegCM(ERA40); (57.26\%)

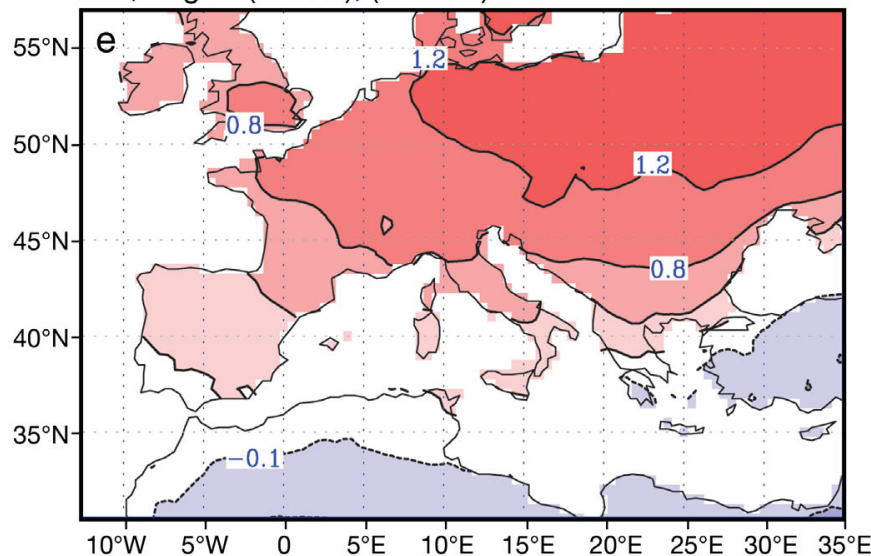

JJA; CRU; (35.28\%)

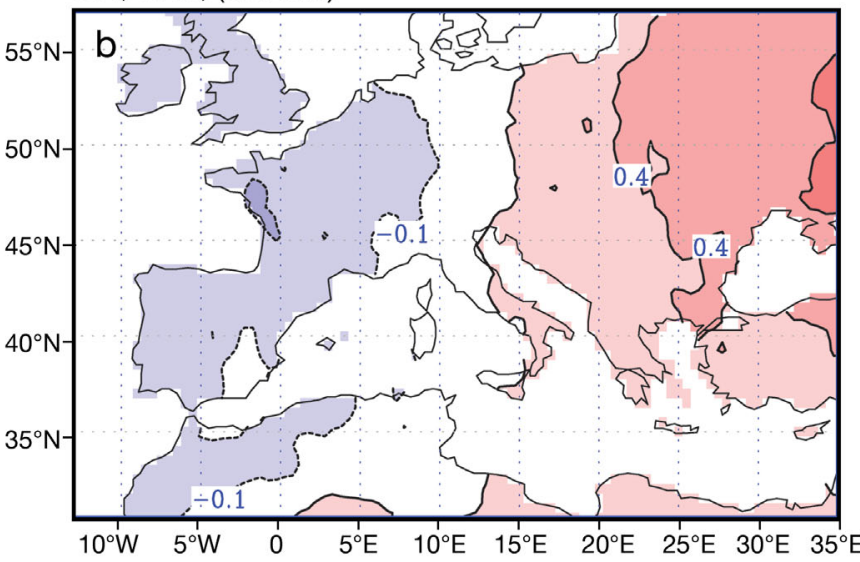

JJA; RegCM; (32.51\%)

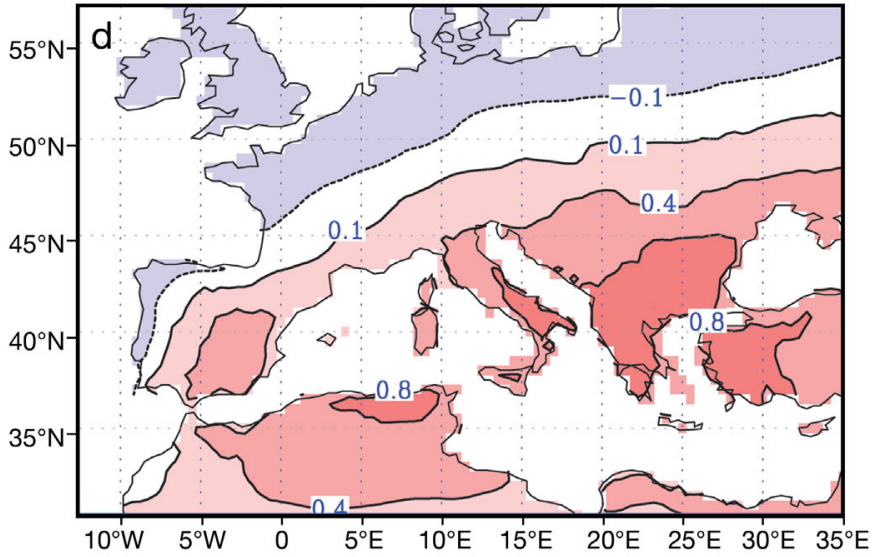

JJA; RegCM(ERA40); (37.15\%)

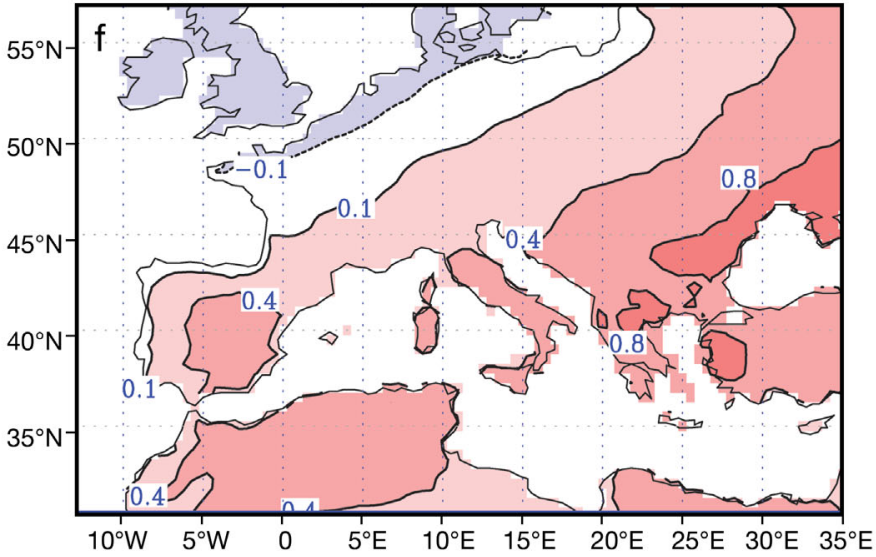

Fig. 3. The first empirical orthogonal function (EOF) spatial patterns for $\mathrm{T} 2 \mathrm{~m}$ in DJF (left) and JJA (right) for CRU (top), RegCM ensemble (middle) and RegCM(ERA40) (bottom) in Period P0. Contours are at $\pm 0.1,0.4,0.8,1.2,1.6$ and 2.0

observed interannual variability reasonably well. With relatively larger systematic errors (as when RegCM is driven by the global model), however, the representation of interannual variability tends to be poorer. Our results for the winter $\mathrm{T} 2 \mathrm{~m}$ are consistent with those of e.g. Branstator \& Selten (2009), who reported that the leading modes of interannual variability are largely constrained by 
the mean state, and would change if the mean state were modified.

In JJA, the differences in the EOF1 pattern between the CRU data and the RegCM model are marked (Fig. 3, right panels). With respect to the CRU data, the largest EOF1 values are observed in the east (Fig. 3b), thereby indicating a stronger temperature variation of a relatively high summer temperature over a vast Euro-Asian landmass than over western Europe, which is under the influence of advection from a persistently cooler (and less variable) northern Atlantic. The east-west pattern similar to that in the CRU EOF1, but explaining only $16 \%$ of the total variance, is captured in the RegCM EOF3 (not shown). Thus, the model is essentially able to reproduce the main pattern of observed variability, but with a considerably reduced share of the total variability. Correlation coefficients in JJA are considerably reduced when compared with DJF, signifying a discrepancy in EOF patterns between various sources (Table 2). However, for the 'matching' patterns, in this case CRU EOF1 and RegCM EOF3, the correlation is $>0.7$. The variance explained by the first 3 summer modes is still relatively large, amounting to between 68 and $72 \%$.

The pattern of RegCM(ERA40) EOF1 (Fig. 3f) is somewhere between the CRU (Fig. 3b) and the RegCM ensemble (Fig. 3d) patterns, but displays a stronger east-west gradient than the gradient depicted in Fig. 3d. When the patterns of interannual variability shown in Fig. $3 \mathrm{~d}$ and $\mathrm{f}$ are related to their respective systematic errors (Fig. 2c and f), a similar consideration as for winter can apply: the better-represented mean state in the model would, in turn, result in a better representation of interannual variability. However, because the observed principle pattern of variability in the summer is best represented by the model's higher order EOFs (with less variance explained), this relationship appears to be weaker in the summer than in the winter.

In addition to boundary forcing, the differences in the explained variance and the correlations between
Table 2. Near-surface temperature (T2m) variance explained by the first $3 \mathrm{em}$ pirical orthogonal functions (EOFs) and cumulative variance (\%) for CRU, RegCM, RegCM(ERA40) and EH5OM in Period P0 (first 4 rows in each season); spatial correlation coefficients between RegCM and CRU, RegCM(ERA40) and CRU, EH5OM and CRU, and RegCM and EH5OM are given. All numbers are for land points only

\begin{tabular}{|c|c|c|c|c|c|}
\hline Quantity & Source & $\begin{array}{c}\text { EOF } \\
1\end{array}$ & $\begin{array}{c}\text { EOF } \\
2\end{array}$ & $\begin{array}{c}\text { EOF } \\
3\end{array}$ & $\begin{array}{l}\text { Cumu- } \\
\text { lative } \\
\text { variance }\end{array}$ \\
\hline \multicolumn{6}{|l|}{ DJF } \\
\hline \multirow[t]{4}{*}{ Explained variance (\%) } & CRU & 64.0 & 14.0 & 9.6 & 87.5 \\
\hline & RegCM & 51.3 & 19.6 & 11.2 & 82.0 \\
\hline & RegCM(ERA40) & 57.3 & 15.6 & 13.1 & 86.0 \\
\hline & EH5OM & 55.7 & 18.4 & 9.7 & 83.8 \\
\hline \multirow[t]{4}{*}{ Spatial correlation } & RegCM, CRU & 0.93 & 0.20 & 0.36 & \\
\hline & RegCM(ERA40), CRU & 0.97 & 0.43 & 0.62 & \\
\hline & EH5OM, CRU & 0.94 & 0.15 & 0.27 & \\
\hline & RegCM, EH5OM & 0.99 & 0.92 & 0.91 & \\
\hline \multicolumn{6}{|l|}{ MAM } \\
\hline \multirow[t]{4}{*}{ Explained variance (\%) } & CRU & 55.7 & 16.2 & 7.5 & 79.4 \\
\hline & RegCM & 41.4 & 19.0 & 15.6 & 76.0 \\
\hline & RegCM(ERA40) & 49.2 & 22.0 & 9.4 & 80.6 \\
\hline & EH5OM & 46.0 & 18.6 & 12.7 & 77.3 \\
\hline \multirow[t]{4}{*}{ Spatial correlation } & RegCM, CRU & 0.72 & 0.48 & 0.26 & \\
\hline & RegCM(ERA40), CRU & 0.96 & 0.88 & 0.92 & \\
\hline & EH5OM, CRU & 0.85 & 0.86 & 0.34 & \\
\hline & RegCM, EH5OM & 0.92 & 0.69 & 0.78 & \\
\hline \multicolumn{6}{|l|}{ JJA } \\
\hline \multirow[t]{4}{*}{ Explained variance (\%) } & CRU & 35.3 & 20.0 & 13.4 & 68.6 \\
\hline & RegCM & 32.5 & 22.3 & 16.1 & 70.9 \\
\hline & RegCM(ERA40) & 37.2 & 24.2 & 11.5 & 72.9 \\
\hline & EH5OM & 35.0 & 19.2 & 18.3 & 72.4 \\
\hline \multirow[t]{4}{*}{ Spatial correlation } & RegCM, CRU & 0.14 & 0.00 & 0.06 & \\
\hline & RegCM(ERA40), CRU & 0.62 & 0.00 & 0.29 & \\
\hline & EH5OM, CRU & 0.35 & 0.60 & 0.75 & \\
\hline & RegCM, EH5OM & 0.27 & 0.70 & 0.39 & \\
\hline \multicolumn{6}{|l|}{ SON } \\
\hline \multirow[t]{4}{*}{ Explained variance (\%) } & CRU & 33.8 & 24.0 & 14.6 & 72.4 \\
\hline & RegCM & 40.0 & 20.2 & 13.9 & 74.2 \\
\hline & RegCM(ERA40) & 34.9 & 24.6 & 14.1 & 73.7 \\
\hline & EH5OM & 48.5 & 18.2 & 11.2 & 77.9 \\
\hline \multirow[t]{4}{*}{ Spatial correlation } & RegCM, CRU & 0.93 & 0.88 & 0.35 & \\
\hline & RegCM(ERA40), CRU & 0.46 & 0.91 & 0.84 & \\
\hline & EH5OM, CRU & 0.89 & 0.85 & 0.46 & \\
\hline & RegCM, EH5OM & 0.90 & 0.96 & 0.94 & \\
\hline
\end{tabular}

RegCM and RegCM(ERA40) may be partially ascribed to the different sample sizes used for their computation. Whereas EOFs from ensemble integrations were derived from 90 values (3 runs of $30 \mathrm{yr}$ each), RegCM(ERA40) EOFs were derived from only $30 \mathrm{yr}$. To determine the impact of sample size, the EOF computation was repeated for each single member of the ensemble, i.e. for the three $30 \mathrm{yr}$ time series. The cumulative explained variance changes slightly across individual RegCM integrations. However, the contributions of the same individual EOF to the total explained variance differed between runs. For exam- 
ple, with respect to EOF1, the largest difference (variation) in the explained variance in the 3 runs was observed in the winter, and the smallest difference was observed in the summer. This result further confirms that the boundary conditions have the largest impact on interannual variability in the winter; in the summer, however, local processes prevail, which are primarily governed by RegCM physics.

\subsection{Precipitation}

All of the major qualitative characteristics of European precipitation, particularly those related to orographic features, are successfully reproduced by the RegCM. However, in all seasons except JJA, the simulated precipitation is larger than observed precipitation over a large portion of the integration domain (Fig. 4). During the winter, discernible positive errors over western Europe (observed in both CRU and EOBS verifications) are associated with excessive rain brought by the Atlantic westerlies. Such errors may be related to the possible impact of lateral boundaries; for example, Branković et al. (2010) indicated large wind errors in EH5OM over Europe during winter, when a strong zonalisation of the westerlies occurs. Data confirming this are shown in Fig. 4e, where the positive bias over western Europe in the RegCM(ERA40) is shown to be reduced when compared with Fig. 4a. However, Fig. 4e also presents data indicating that the excessive winter precipitation over many parts of Europe is a genuine RegCM error.

The largest negative errors in precipitation are found in JJA over the northern Mediterranean region and southeastern Europe (Fig. 4c). These errors in precipitation projection are associated with positive errors in simulated mean sea-level pressure (MSLP; not shown). Specifically, in the region south of $50^{\circ} \mathrm{N}$, the MSLP in the RegCM ensemble was higher than in ERA-40 in each year of the 30 yr period, eventually amounting to an average increase of $>3 \mathrm{hPa}$ in the northern Mediterranean region. If the model results are verified against EOBS data, the negative bias over southern and southeastern Europe is generally smaller than is shown in Fig. 4c and is locally up to $1 \mathrm{~mm} \mathrm{~d}^{-1}$. In RegCM(ERA40), errors in JJA are generally reduced (Fig. 4f). A relatively large negative bias, however, appears to be inherent to RegCM, particularly in the Alpine region (also seen in EOBS verification). Most of the precipitation errors described above are statistically significant at the $95 \%$ confidence level; the significance is somewhat re- duced over the Mediterranean region in the spring and autumn and over central and eastern Europe in the summer.

Giorgi et al. (2004a) and Park et al. (2008) also noted the tendency of the RegCM mean precipitation to be larger than is observed, although they used different model versions, and their integrations were made for different regions of the world. Giorgi et al. (2004a) also noted that CRU data over Europe compared with, for example, the verification data from Willmott \& Matsuura (2001), may underestimate precipitation by $<10 \%$ in the warm season to $>25-35 \%$ over the mountains in the winter. For our analysis, this would imply, for example, that the largest summer dry bias in the eastern Alps of approximately $-2 \mathrm{~mm} \mathrm{~d}^{-1}$ (Fig. 4c) would be even larger with respect to the data published by Willmott \& Matsuura (2001), thereby amounting to $-2.4 \mathrm{~mm} \mathrm{~d}^{-1}$. Alternatively, assuming that CRU data are underestimated by $30 \%$ in winter, the largest wet bias of $3 \mathrm{~mm} \mathrm{~d}^{-1}$ in the Alpine region (Fig. 4a) would be reduced to $2.4 \mathrm{~mm} \mathrm{~d}^{-1}$.

The patterns of interannual variability as defined by the CRU EOF1 in DJF and JJA reveal 2 distinct action centres of reversed polarity: 1 centre in northern Europe and 1 centre in southern Europe (Fig. 5). The similarity between Fig. 5a,b and the corresponding figures from Zveryaev (2006) is striking, even with respect to the proportion of the total variance explained, although these studies cover time periods of very different lengths (30 vs. 100 yr). In DJF (Fig. 5a), the largest loadings are located in the western coastal regions of the UK, the Iberian Peninsula, the Balkans and Turkey, indicating that the primary component of variability is found over the regions that are most exposed to moisture-laden winds from the sea. This feature is reproduced well in the RegCM, and in more detail (Fig. 5c). The EOF1 shown in Fig. 5 explains a smaller fraction of the total variance than in Fig. 3, indicating that in terms of precipitation, the other modes of variability are almost equally important. With respect to EOF1, the DJF correlation coefficients between each model and CRU data are notably high (nearly 0.75 ; Table 3 ), although not as high as for $\mathrm{T} 2 \mathrm{~m}$. Although in many respects the EOF1 pattern in RegCM(ERA40) (Fig. 5e) is similar to that shown in Fig. 5c, it agrees more strongly with CRU data in central-northern Europe, the region that is distant from the influence of lateral boundaries.

In JJA, the EOF1 patterns for CRU and RegCM are similar (Fig. 5b,d). In the far north, where the Atlantic westerlies dominate the summer precipitation re- 


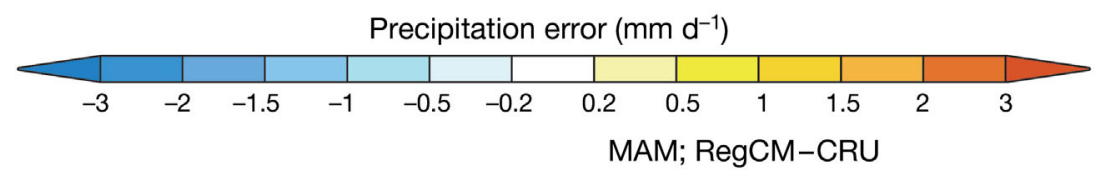

DJF; RegCM-CRU

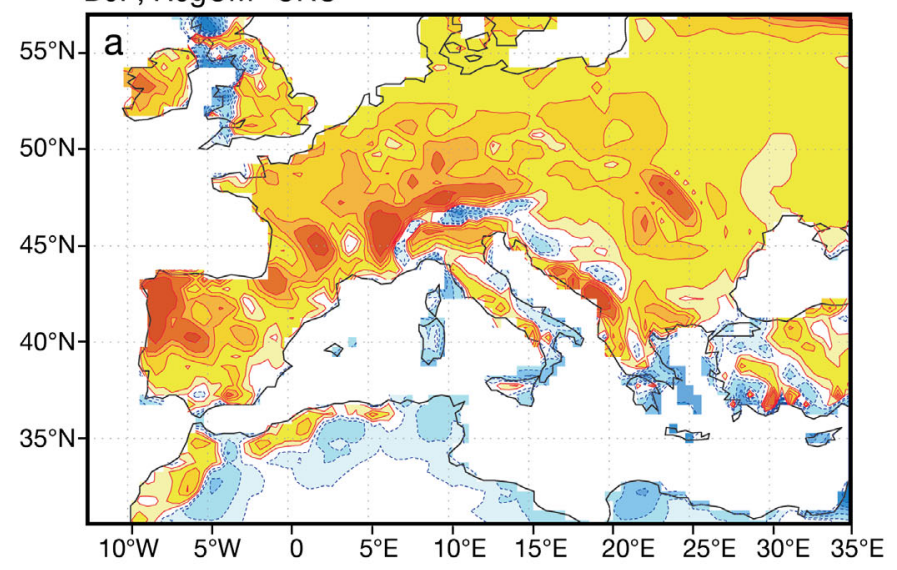

JJA; RegCM-CRU

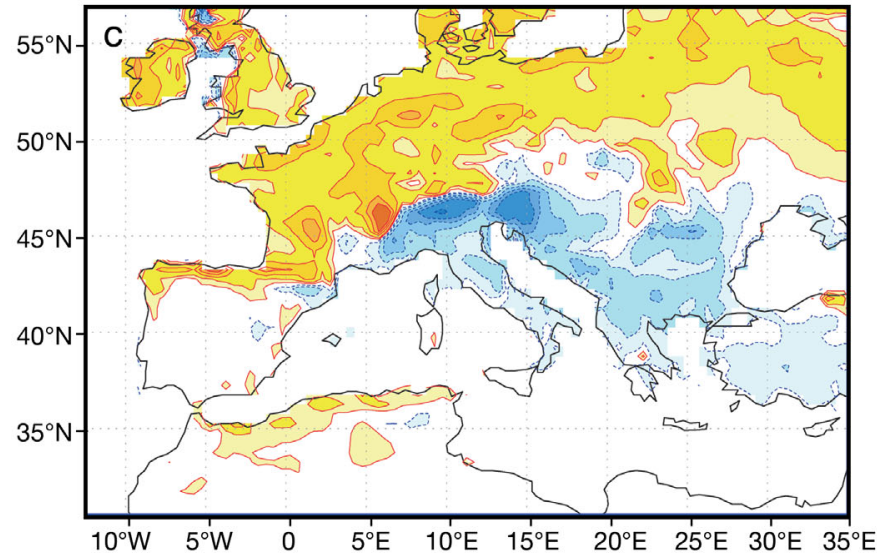

DJF; RegCM(ERA40)-CRU

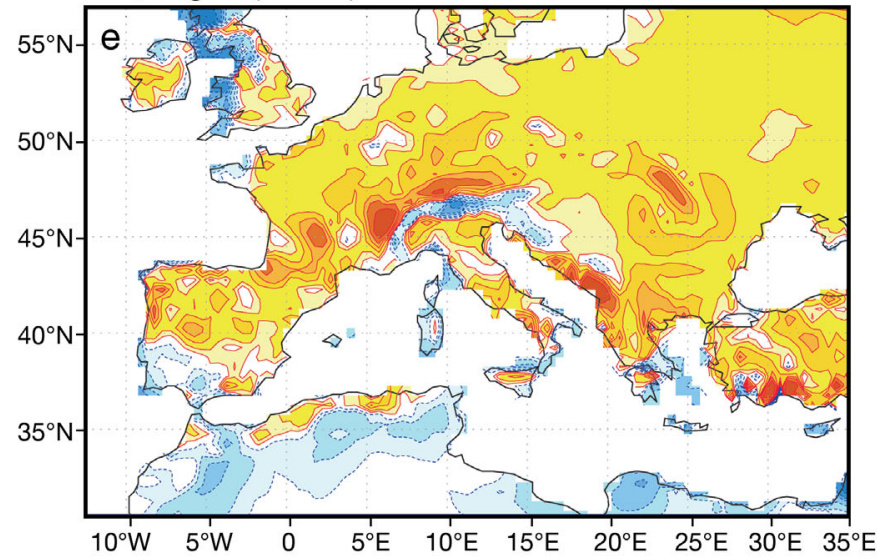

MAM; RegCM-CRU

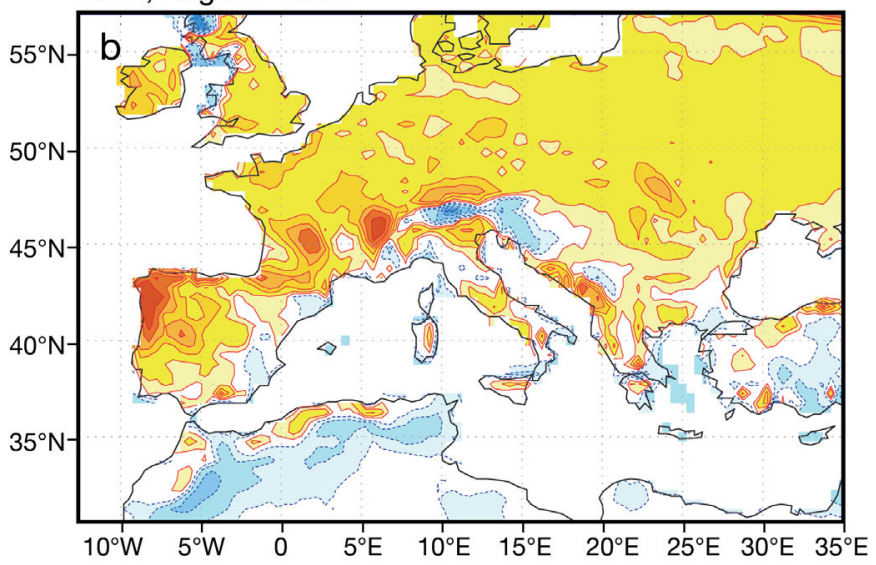

SON; RegCM-CRU

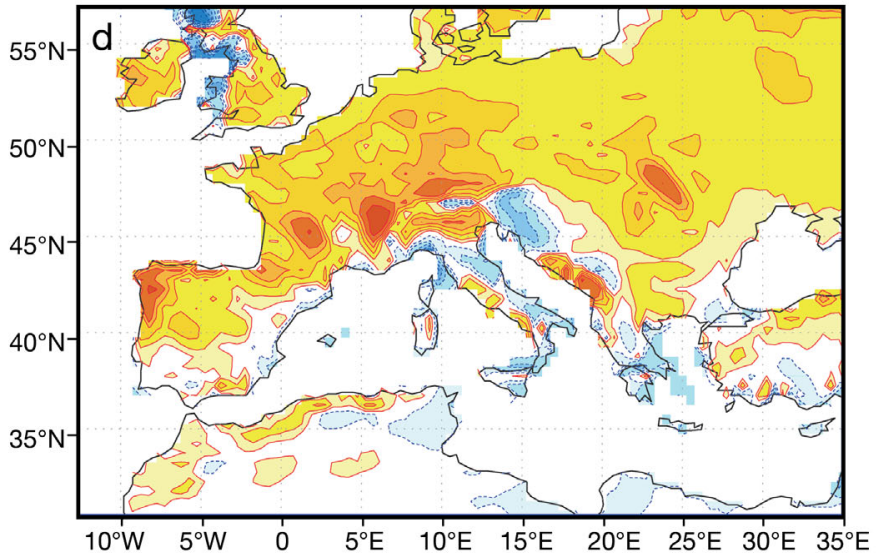

JJA; RegCM(ERA40)-CRU

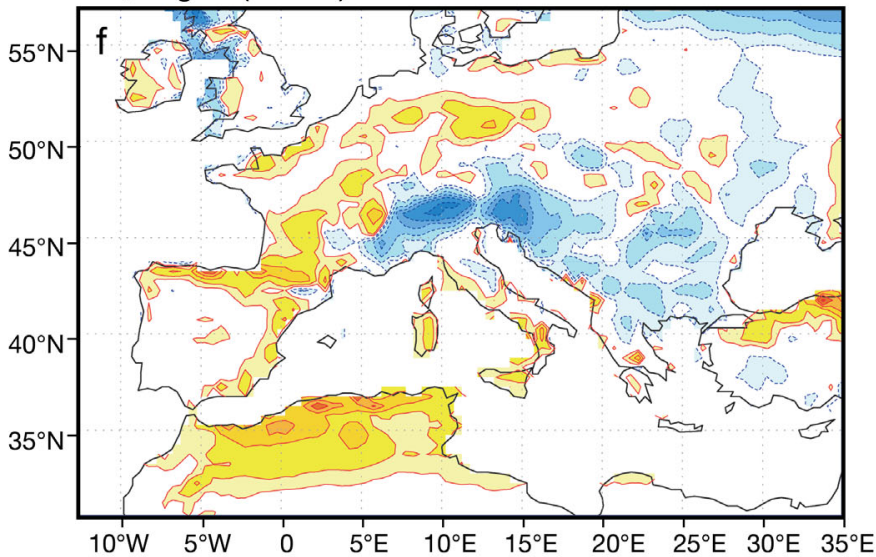

Fig. 4. Errors as in Fig. 2, but for total precipitation. Contours are at $\pm 0.2,0.5,1,1.5,2$ and $3 \mathrm{~mm} \mathrm{~d}^{-1}$

gime, the pattern of variability is linked with the North Atlantic Oscillation (Folland et al. 2009). In southern Europe (south of $45^{\circ} \mathrm{N}$ ), the RegCM closely follows CRU data. This finding indicates that a model with a relatively high horizontal resolution can cor- rectly capture the main part of interannual variation in precipitation over southern Europe. This is possibly because the predominantly convective precipitation in summer is associated with relatively smallscale features. In the corresponding EOF1 pattern for 


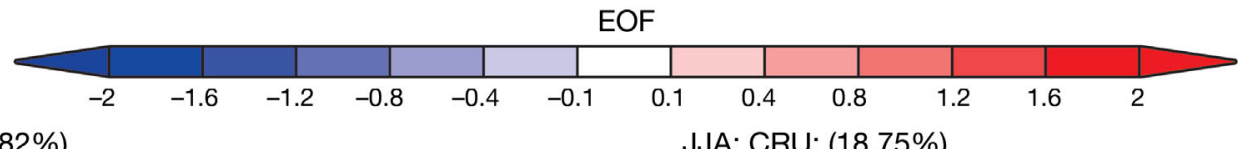

DJF; CRU; (27.82\%)

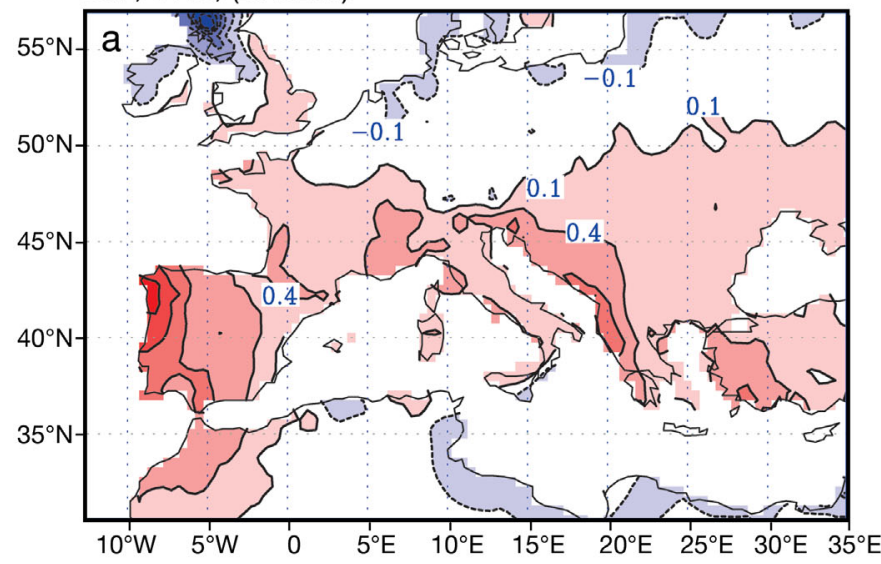

DJF; RegCM; (28.79\%)

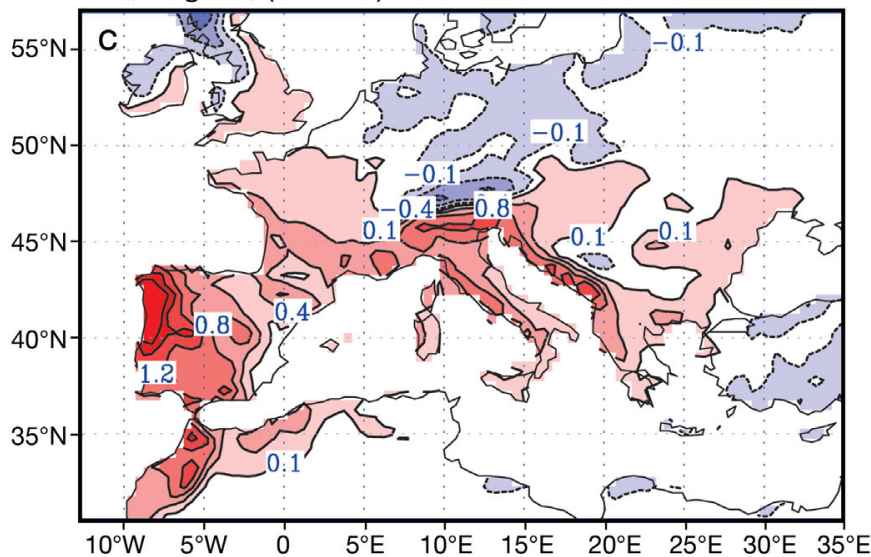

DJF; RegCM(ERA40); (28.55\%)

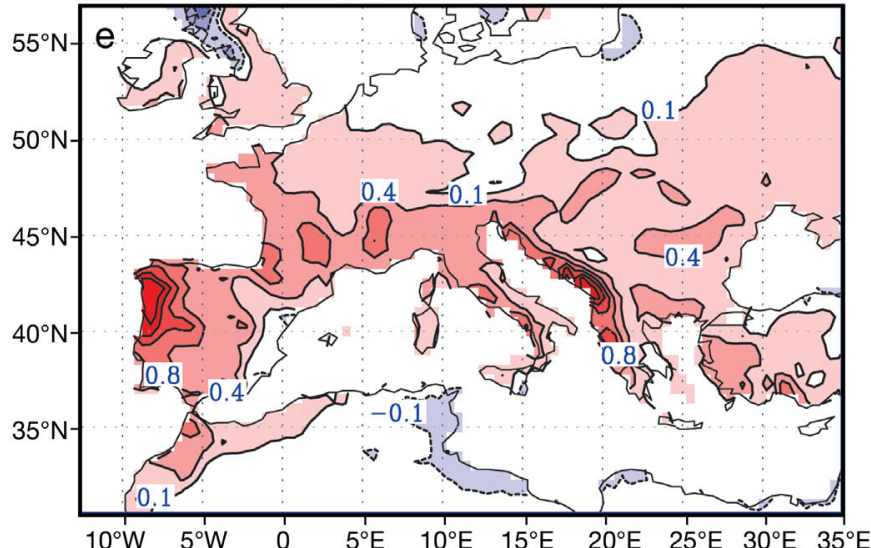

JJA; CRU; (18.75\%)

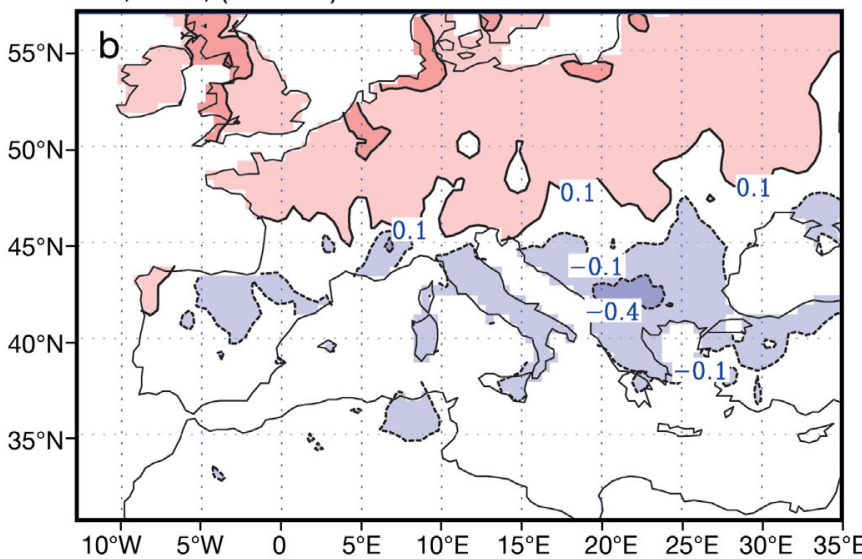

JJA; RegCM; (18.19\%)

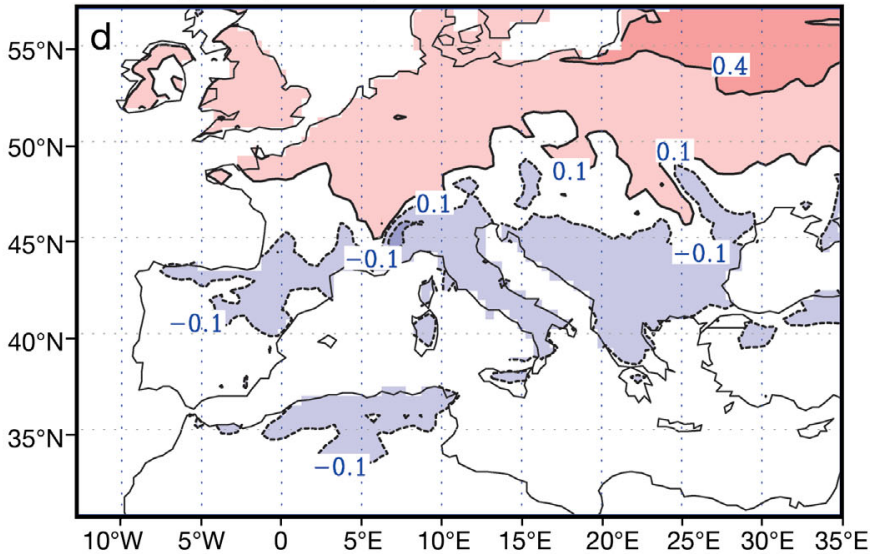

JJA; RegCM(ERA40); (20.29\%)

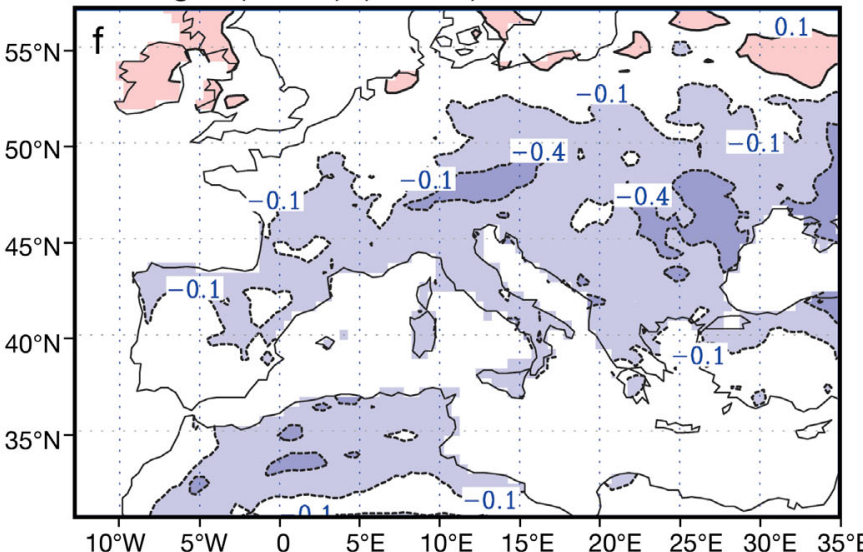

Fig. 5. First empirical function (EOF) spatial patterns as in Fig. 3, but for total precipitation

the EH5OM AOGCM, only the weak loadings north of $45^{\circ} \mathrm{N}$ are indicated, with no loadings to the south (not shown). The EH5OM AOGCM pattern is completely devoid of the spatial variability details observed in the CRU or RegCM patterns. Such a differ- ence between RegCM and EH5OM clearly suggests the added value obtained by using a RCM to represent the interannual variability in precipitation. Although the EOF1 patterns in the RegCM ensemble (Fig. 5d) and RegCM(ERA40) (Fig. 5f) look different, 
the RegCM(ERA40) EOF2 pattern matches that shown in Fig. 5d. This finding would imply that the same regional model could generate similar patterns of variability (possibly with a different percentage of the total variance explained), even with different lateral boundary forcing. One possible explanation is that in the summer, when the advection from the boundaries is relatively weak, the RCM physics has the principle impact on simulated interannual variability.

\section{CLIMATE CHANGE IN THE NEAR FUTURE}

The choice of the near-future period (2011-2040) may have important implications for the discussion of regional climate change. For example, a general consensus among climate models for the IPCC A2 scenario indicates that global surface temperature warming would be approximately 3 times greater at the end of 21st century than in 2040 (Meehl et al. 2007). Locally, the magnitude of warming may be even higher than the global average, particularly over southern Europe and the Mediterranean, the regions defined as climate change 'hot spots' (Giorgi 2006). Such a strong signal at the end of the 21st century will certainly overwhelm the model's systematic error. Conversely, when the analysed time period is in the near future, model biases may be comparable with the climate signal itself, and the interpretation of any observed climate change would be more uncertain (for example, see Hawkins \& Sutton 2009 for a discussion of how various uncertainties impact climate modelling).

\subsection{Changes in $\mathrm{T} 2 \mathrm{~m}$}

A clearly expressed seasonality is the primary feature of the near-surface temperature all-season warming between Periods P1 and P0 (Fig. 6a-d). Larger warming amplitudes are observed in the
Table 3. As in Table 2 but for precipitation

\begin{tabular}{|c|c|c|c|c|c|}
\hline Quantity & Source & $\begin{array}{c}\mathrm{EOF} \\
1\end{array}$ & $\begin{array}{c}\mathrm{EOF} \\
2\end{array}$ & $\begin{array}{c}\mathrm{EOF} \\
3\end{array}$ & $\begin{array}{c}\text { Cumu- } \\
\text { lative } \\
\text { variance }\end{array}$ \\
\hline \multicolumn{6}{|l|}{ DJF } \\
\hline \multirow[t]{4}{*}{ Explained variance (\%) } & CRU & 27.8 & 16.5 & 13.7 & 58.0 \\
\hline & RegCM & 28.8 & 13.7 & 11.5 & 54.0 \\
\hline & RegCM(ERA40) & 28.6 & 14.6 & 14.1 & 57.2 \\
\hline & EH5OM & 31.7 & 16.6 & 13.7 & 62.0 \\
\hline \multirow[t]{4}{*}{ Spatial correlation } & RegCM, CRU & 0.73 & 0.69 & 0.45 & \\
\hline & RegCM(ERA40), CRU & 0.78 & 0.55 & 0.68 & \\
\hline & EH5OM, CRU & 0.74 & 0.77 & 0.65 & \\
\hline & RegCM, EH5OM & 0.86 & 0.82 & 0.77 & \\
\hline \multicolumn{6}{|l|}{ MAM } \\
\hline \multirow[t]{4}{*}{ Explained variance (\%) } & CRU & 19.2 & 13.4 & 10.2 & 42.8 \\
\hline & RegCM & 21.7 & 14.2 & 9.8 & 45.7 \\
\hline & RegCM(ERA40) & 19.6 & 15.9 & 10.4 & 45.9 \\
\hline & EH5OM & 26.8 & 17.5 & 11.0 & 55.3 \\
\hline \multirow[t]{4}{*}{ Spatial correlation } & RegCM, CRU & 0.11 & 0.11 & 0.45 & \\
\hline & RegCM(ERA40), CRU & 0.81 & 0.65 & 0.60 & \\
\hline & EH5OM, CRU & 0.16 & 0.35 & 0.56 & \\
\hline & RegCM, EH5OM & 0.79 & 0.76 & 0.85 & \\
\hline \multicolumn{6}{|l|}{ JJA } \\
\hline \multirow[t]{4}{*}{ Explained variance (\%) } & CRU & 18.8 & 15.3 & 11.0 & 45.1 \\
\hline & RegCM & 18.2 & 9.7 & 7.1 & 34.9 \\
\hline & RegCM(ERA40) & 20.3 & 13.4 & 10.1 & 43.8 \\
\hline & EH5OM & 25.9 & 17.1 & 9.8 & 52.8 \\
\hline \multirow[t]{4}{*}{ Spatial correlation } & RegCM, CRU & 0.70 & 0.45 & 0.07 & \\
\hline & RegCM(ERA40), CRU & 0.43 & 0.10 & 0.47 & \\
\hline & EH5OM, CRU & 0.61 & 0.73 & 0.12 & \\
\hline & RegCM, EH5OM & 0.68 & 0.69 & 0.82 & \\
\hline \multicolumn{6}{|l|}{ SON } \\
\hline \multirow{4}{*}{ Explained variance (\%) } & CRU & 22.2 & 14.5 & 10.3 & 46.9 \\
\hline & RegCM & 17.1 & 14.3 & 9.4 & 40.7 \\
\hline & RegCM(ERA40) & 21.1 & 14.1 & 13.6 & 48.9 \\
\hline & EH5OM & 23.0 & 17.6 & 11.9 & 52.5 \\
\hline \multirow[t]{4}{*}{ Spatial correlation } & RegCM, CRU & 0.12 & 0.34 & 0.67 & \\
\hline & RegCM(ERA40), CRU & 0.80 & 0.46 & 0.07 & \\
\hline & EH5OM, CRU & 0.11 & 0.40 & 0.53 & \\
\hline & RegCM, EH5OM & 0.83 & 0.86 & 0.80 & \\
\hline
\end{tabular}

warmer part of the year (JJA, SON) than in the colder seasons (DJF, MAM) in southern and central Europe. In DJF (Fig. 6a), the northeast-to-southwest temperature gradient across continental Europe is a combination of a relatively weak warming over the Atlantic and strong warming over eastern Europe, because of a weakened snow-albedo feedback, which is primarily responsible for low temperatures in the present climate (Rowell 2005). The climate change (for 2011-2040) shown in Fig. 6a has a similar pattern but a weaker amplitude than that of the 6-member A1B ensemble described in Kjellström et al. (2011). The temperature changes in DJF and MAM are statistically significant at the $95 \%$ confidence level over a large portion of the domain. 


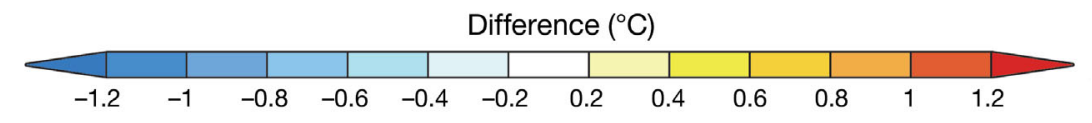

T2m; DJF

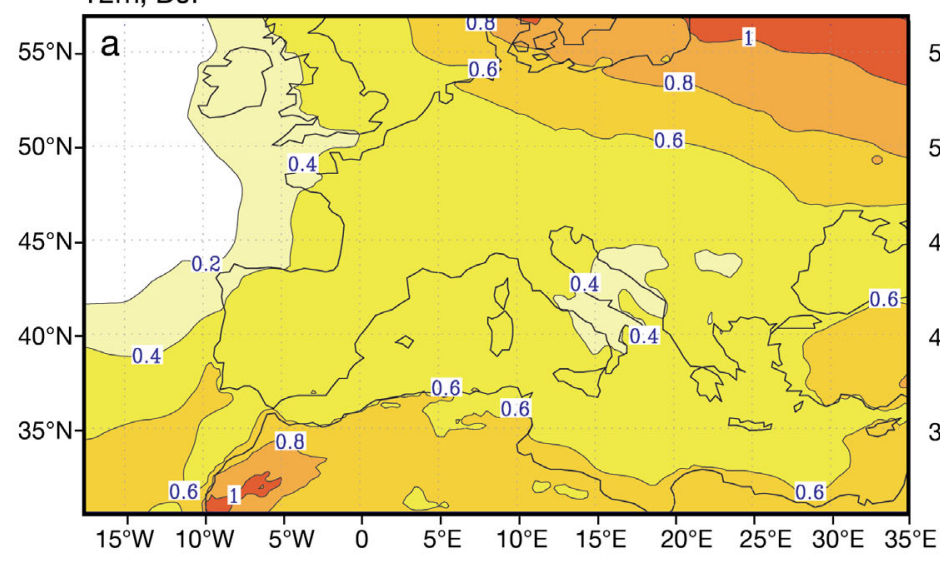

T2m; JJA

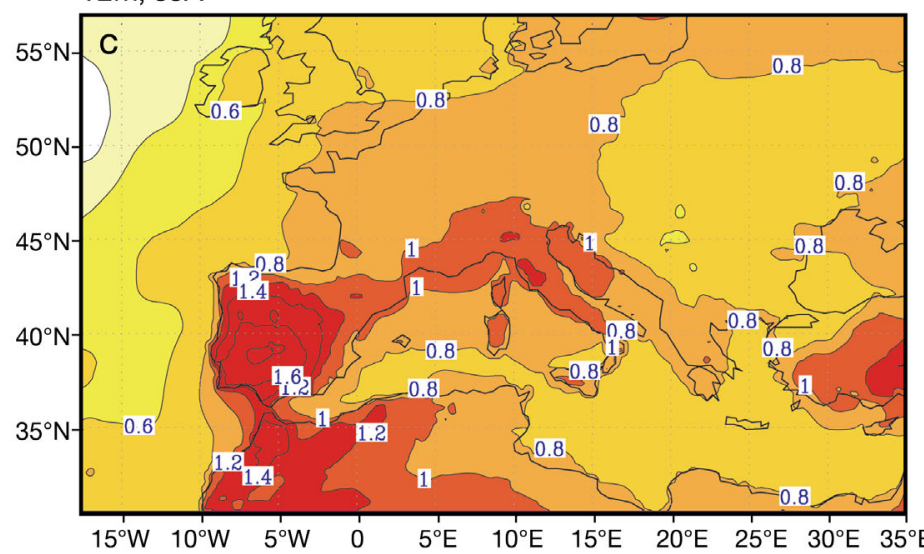

T2min; DJF

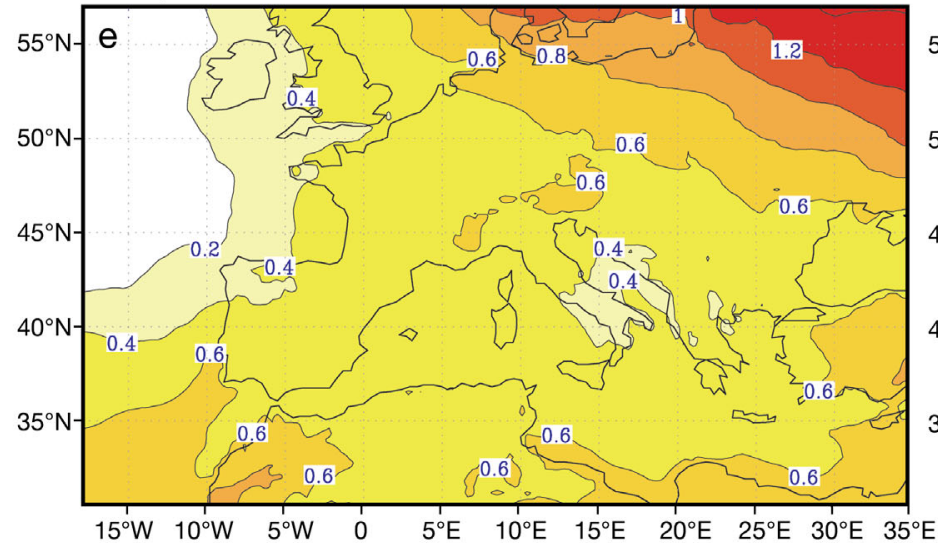

T2m; MAM

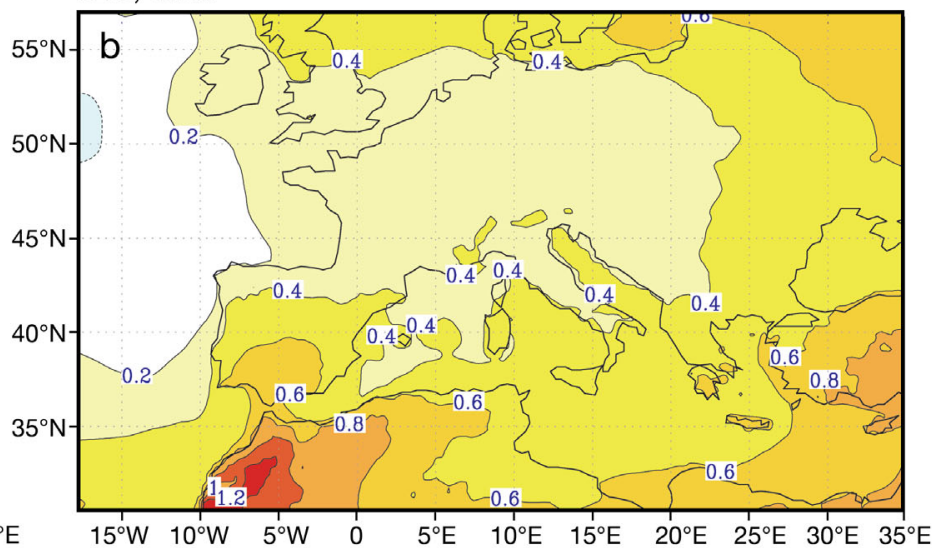

T2m; SON

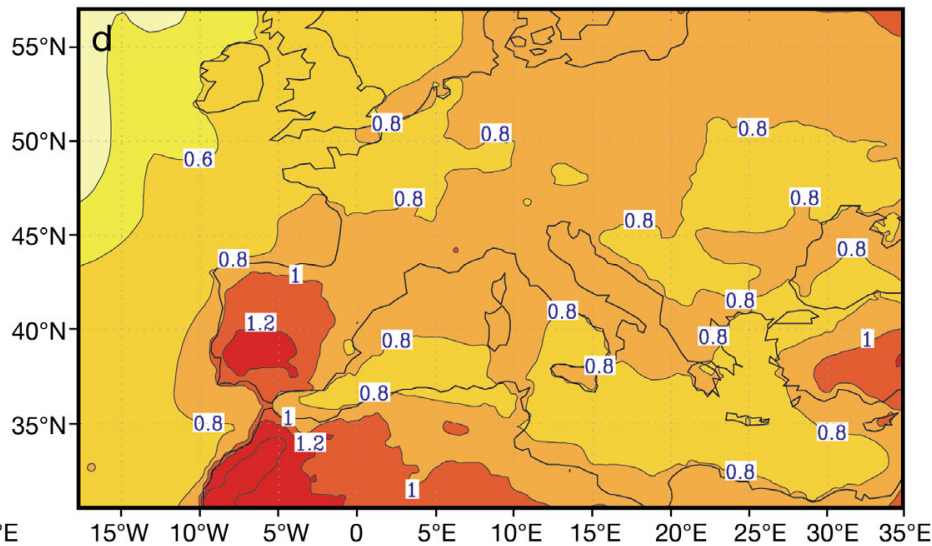

T2max; JJA

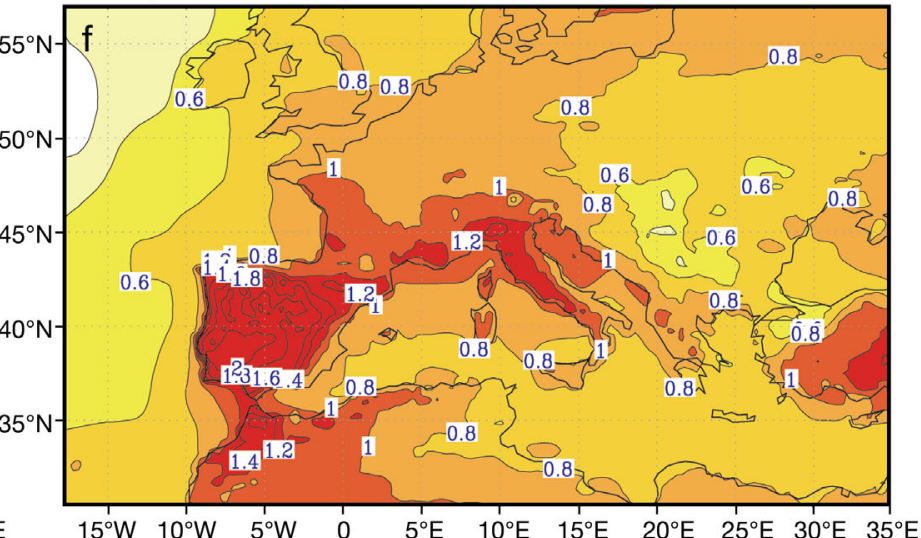

Fig. 6. Ensemble-mean differences between Periods P1 and P0 for T2m during (a) DJF, (b) MAM, (c) JJA and (d) SON and for (e) T2min in DJF and (f) T2max in JJA. Contours every $\pm 0.2^{\circ} \mathrm{C}$

In JJA (Fig. 6c), the warming is strongest in southern Europe and the Mediterranean region, reaching $1.8^{\circ} \mathrm{C}$ over the Iberian Peninsula; in SON (Fig. 6d), a somewhat reduced amplitude of warming over southern Europe is observed. Although this is far below the warming obtained by downscaling studies for the late 21st century (e.g. Giorgi et al. 2004b, Déqué et al. 2005, Christensen \& Christensen 2007, Kjellström et al. 2011), it is nevertheless statistically significant at the $99 \%$ confidence level. Thus, in 
response to the increased concentrations of GHGs in the A2 scenario, a major increase in T2m over Europe is projected even for the near future. As discussed in the previous section, however, the non-negligible systematic biases in $\mathrm{T} 2 \mathrm{~m}$ may have a relatively strong effect on such near-future warming, and the temperature rise should be interpreted with a degree of caution. In the northeastern portion of the domain, for example, the strongest warming in DJF coincides with relatively large positive errors (Fig. 2a). It may be hypothesised that overly warm winters in the reference climate will warm to a lesser degree in a warming climate because of decreased snow available for melting, i.e. the snow-albedo feedback would be less effective. In contrast, the strongest warming during JJA in the southwestern portion of the Iberian Peninsula (Fig. 6c) coincides with a small or negligible bias (Fig. 2c) and could be more certain than, for example, the warming of $>1^{\circ} \mathrm{C}$ that extends from northern Spain across southern France into central Europe, coinciding with the large cold bias.

With respect to $\mathrm{T} 2 \mathrm{~min}$, the strongest warming in DJF is over the northeastern portion of the domain (Fig. 6e); for T2max, the strongest warming in JJA is over the Iberian Peninsula (Fig. 6f). Hence, warm extremes will become much warmer, and cold extremes will become less cold (see, for example, Meehl et al. 2009). That is, nights in the cold regions and days in the warm regions will become markedly warmer in P1 than in P0. However, as discussed in Section 3.1, the errors in T2min for DJF and in T2max for other seasons are larger than the errors for $\mathrm{T} 2 \mathrm{~m}$, and, together with significance tests, imply that projected changes in temperature within the diurnal cycle should be interpreted cautiously.

The warming amplitude shown in Fig. 6 is weaker than that predicted from the PRUDENCE models for the years 2071-2100, but the warming patterns are quite similar (e.g. Räisänen et al. 2004, Déqué et al. 2005). Our simulations thus indicate that the primary pattern of climate change over Europe is already established in the near future. This change will be maintained through- out the 21st century, implying that the physical and dynamic processes that initiate and maintain the described climate changes are likely to be identical irrespective of the time period and model considered. These simulations ultimately point to increased GHGs concentrations as the prime source of future climate change over the European/Mediterranean region.

Interannual variability of $\mathrm{T} 2 \mathrm{~m}$ in the future climate, as in Section 3, is discussed here in terms of EOF analysis. In DJF, the pattern of variability in P1 (not shown) will not change a great deal with respect to the pattern in P0 (Fig. 3c). The east-west gradient and the maximum of the EOF1 loading over the domain of European Russia define the variation in the positioning of snow cover associated with yearto-year changes in snow-albedo feedback. Interannual variation in DJF is largely dominated by the EOF1 pattern, contributing in this case to $57 \%$ of the total explained variance in RegCM (Table 4). EOF correlation coefficients between the models (3rd row,

Table 4. Near-surface temperature (T2m) variance explained by the first 3 empirical orthogonal functions (EOFs) and cumulative variance (\%) for RegCM and EH5OM in Period P1 (first 2 rows for each station); spatial correlation coefficients between RegCM and EH5OM in Period P1, for RegCM between Periods P0 and P1, and for EH5OM between Periods P0 and P1. All numbers are for land points only

\begin{tabular}{|c|c|c|c|c|c|}
\hline Quantity & Source & $\begin{array}{c}\text { EOF } \\
1\end{array}$ & $\begin{array}{c}\text { EOF } \\
2\end{array}$ & $\begin{array}{c}\mathrm{EOF} \\
3\end{array}$ & $\begin{array}{l}\text { Cumu- } \\
\text { lative } \\
\text { variance }\end{array}$ \\
\hline \multicolumn{6}{|l|}{ DJF } \\
\hline Explained variance (\%) & $\begin{array}{l}\text { RegCM } \\
\text { EH5OM }\end{array}$ & $\begin{array}{l}56.5 \\
63.9\end{array}$ & $\begin{array}{l}17.7 \\
15.0\end{array}$ & $\begin{array}{r}12.2 \\
9.6\end{array}$ & $\begin{array}{l}86.3 \\
88.5\end{array}$ \\
\hline Spatial correlation & $\begin{array}{l}\text { RegCM, EH5OM (P1) } \\
\text { RegCM (P0, P1) } \\
\text { EH5OM (P0, P1) }\end{array}$ & $\begin{array}{l}0.99 \\
0.98 \\
0.99\end{array}$ & $\begin{array}{l}0.95 \\
0.80 \\
0.76\end{array}$ & $\begin{array}{l}0.96 \\
0.82 \\
0.81\end{array}$ & \\
\hline \multicolumn{6}{|l|}{ MAM } \\
\hline Explained variance (\%) & $\begin{array}{l}\text { RegCM } \\
\text { EH5OM }\end{array}$ & $\begin{array}{l}45.4 \\
49.1\end{array}$ & $\begin{array}{l}22.4 \\
20.8\end{array}$ & $\begin{array}{l}12.6 \\
10.1\end{array}$ & $\begin{array}{l}80.3 \\
80.0\end{array}$ \\
\hline Spatial correlation & $\begin{array}{l}\text { RegCM, EH5OM (P1) } \\
\text { RegCM (P0, P1) } \\
\text { EH5OM (P0, P1) }\end{array}$ & $\begin{array}{l}0.98 \\
0.96 \\
0.99\end{array}$ & $\begin{array}{l}0.97 \\
0.53 \\
0.82\end{array}$ & $\begin{array}{l}0.90 \\
0.61 \\
0.84\end{array}$ & \\
\hline \multicolumn{6}{|l|}{ JJA } \\
\hline Explained variance (\%) & $\begin{array}{l}\text { RegCM } \\
\text { EH5OM }\end{array}$ & $\begin{array}{l}29.8 \\
37.6\end{array}$ & $\begin{array}{l}26.4 \\
22.3\end{array}$ & $\begin{array}{l}13.0 \\
12.2\end{array}$ & $\begin{array}{l}69.1 \\
72.1\end{array}$ \\
\hline Spatial correlation & $\begin{array}{l}\text { RegCM, EH5OM (P1) } \\
\text { RegCM (P0, P1) } \\
\text { EH5OM (P0, P1) }\end{array}$ & $\begin{array}{l}0.72 \\
0.87 \\
0.75\end{array}$ & $\begin{array}{l}0.80 \\
0.88 \\
0.98\end{array}$ & $\begin{array}{l}0.73 \\
0.74 \\
0.94\end{array}$ & \\
\hline SON & & & & & \\
\hline Explained variance (\%) & $\begin{array}{l}\text { RegCM } \\
\text { EH5OM }\end{array}$ & $\begin{array}{l}35.3 \\
39.3\end{array}$ & $\begin{array}{l}19.5 \\
20.5\end{array}$ & $\begin{array}{l}17.1 \\
14.3\end{array}$ & $\begin{array}{l}71.9 \\
74.2\end{array}$ \\
\hline Spatial correlation & $\begin{array}{l}\text { RegCM, EH5OM (P1) } \\
\text { RegCM (P0, P1) } \\
\text { EH5OM (P0, P1) }\end{array}$ & $\begin{array}{l}0.93 \\
0.94 \\
0.98\end{array}$ & $\begin{array}{l}0.95 \\
0.96 \\
0.98\end{array}$ & $\begin{array}{l}0.96 \\
0.96 \\
0.94\end{array}$ & \\
\hline
\end{tabular}



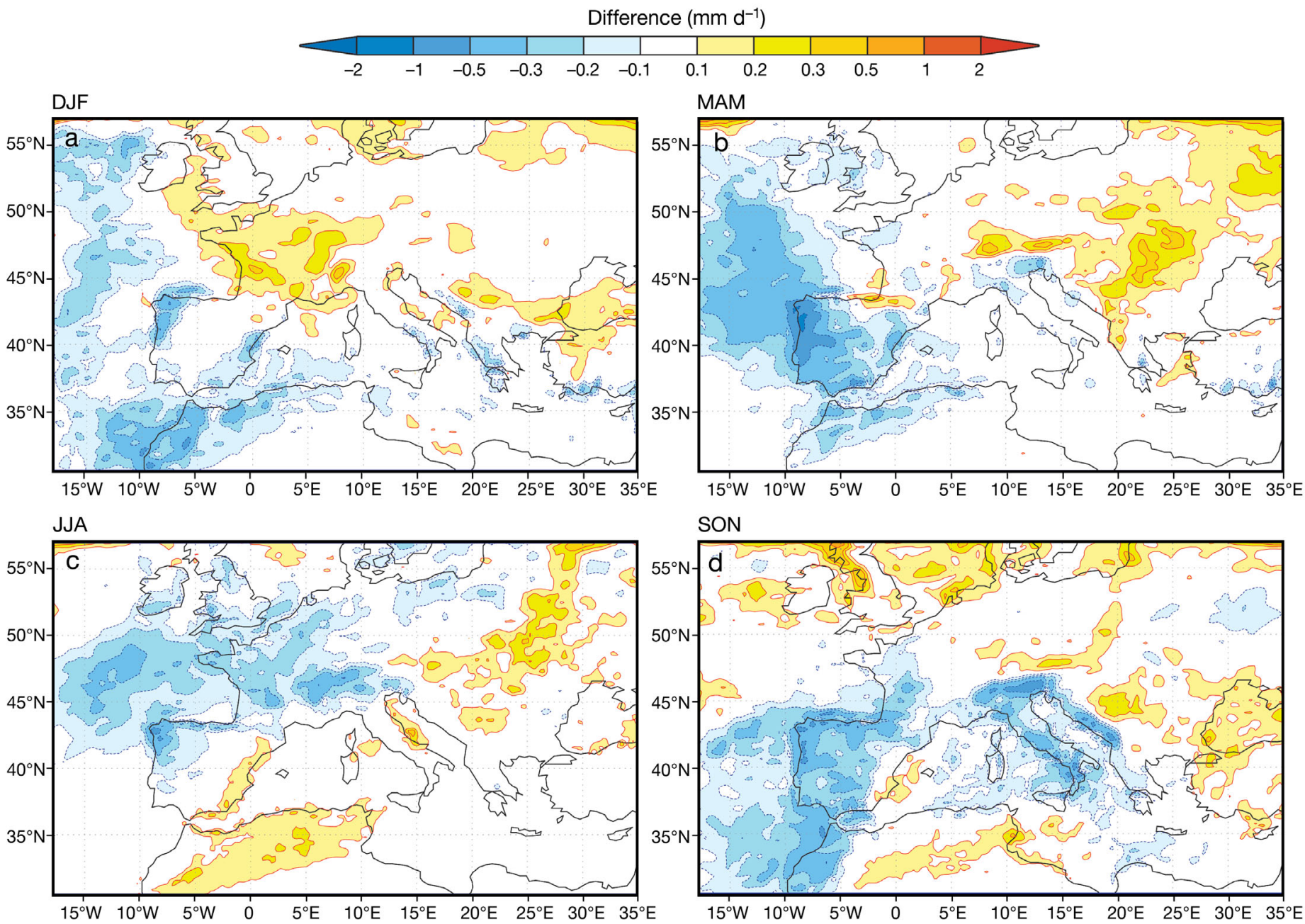

Fig. 7. Ensemble-mean differences between Periods P1 and P0 for total precipitation during (a) DJF, (b) MAM, (c) JJA and (d) SON. Contours are at $\pm 0.1,0.2,0.3,0.5,1$ and $2 \mathrm{~mm} \mathrm{~d}^{-1}$

Table 4) are high, indicating that interannual variation in RegCM is primarily governed by forcing at the lateral boundaries. Consistency in the pattern of interannual variability between the 2 periods is further confirmed by high correlations for the first 3 EOFs (last 2 rows for DJF in Table 4).

In JJA, the EOF1 pattern is similar to that for the reference period (Fig. 3d). However, it differs from that described in e.g. Rowell (2005). Rowell's study, for the period 2071-2100, reported relatively strong interannual variations in the summer, and ascribed such a strong variability to extensive continental drying observed during the summer. Different model responses are also likely to be dependent on the choice of RCM, as their results tend to differ significantly in terms of T2m during JJA, as shown in e.g. Déqué et al. (2005). The comparably weaker variability in $\mathrm{T} 2 \mathrm{~m}$ in our experiments may indicate that the mechanisms responsible for excessive sum- mer warming (e.g. Rowell 2005, Christensen et al. $2007 \mathrm{~b}$ ) are less pronounced in the near future than toward the end of the century.

\subsection{Changes in precipitation}

In contrast to the consistently positive sign of climate change for T2m (Fig. 6), the patterns of precipitation differences between P1 and P0 vary in sign regionally and between seasons (Fig. 7). Predominant differences (positive as well as negative) rarely exceed $0.3 \mathrm{~mm} \mathrm{~d}^{-1}$, which constitutes, on average, a 5 to $10 \%$ change relative to the reference climate. Fig. 7 a shows a hint of the 'partitioning' between the wetter north and the drier south in the future winter climate, as projected for the period 2071-2100 (Giorgi et al. 2004b, Déqué et al. 2005, Christensen \& Christensen 2007, Kjellström et al. 2011). Kjellström 
et al. (2011) also reported a much weaker response for 2011-2040 than for 2071-2100. The increase in precipitation in the north may be related to a weak differential (P1 minus P0) cyclonic circulation over northwestern and central Europe and, therefore, is at least partly associated with increased upper-air winds (not shown). A statistically significant decrease in precipitation in the southwestern portion of the domain cannot, however, be linked to changes in MSLP, as suggested by Giorgi et al. (2004b) for the period 2071-2100. This decrease can, however, be associated with a reduction in lower tropospheric humidity, which is linked to a reduction in soil moisture and a relatively strong increase in sensible heat flux. A similar consideration may be applied to the reduction of precipitation seen in the western portion of the Iberian Peninsula during MAM (Fig. 7b). The increase in precipitation over eastern Europe, however, can be linked to a reduction in MSLP (not shown).

In JJA (Fig. 7c), the largest reduction of precipitation is projected to occur in the Alpine region and in the westernmost Iberian Peninsula. Such a reduction is statistically significant and, in locations in southwestern Europe, amounts to approximately $25 \%$ less precipitation relative to the reference climate. The pattern of change presented in Fig. 7c differs from that observed for the late 21st century, which is characterised by a decrease in precipitation levels over most of Europe relative to 20th century climate (e.g. Giorgi et al. 2004b, Räisänen et al. 2004, Déqué et al. 2005, Kjellström et al. 2011). The differences are primarily over southern Europe and the Mediterranean region. This finding suggests that the pattern of precipitation change in the late 21st century will be established only after the period considered here. This finding may have important implications with respect to adaptations to climate change, particularly in the Mediterranean basin, given that such a climate change pattern may require different approaches and strategies in the near future than will be needed later in the 21 st century.

The largest decrease in total precipitation is likely to occur in SON (Fig. 7d), particularly over southern Europe. Over the Alps and in the
Adriatic region, the reduction would be in excess of 45-50 mm season ${ }^{-1}$. The reduction in precipitation presented in Fig. $7 d$ is related to continuous drying of the soil following summer, an event that is associated with the pan-European increase in MSLP. SON is the season for which the largest increase in MSLP is observed (not shown), and the reason for such an increase may be related to a general increase in MSLP on all days over the entire season.

The DJF interannual variation of precipitation, as described by EOF1, is in P1 (not shown), similar to what is observed in P0 (Fig. 5c). This finding implies that the pattern of variability (and possibly its causes) would not change a great deal in the near future. The largest EOF1 loadings in P1 are in western and southern Europe. As discussed with respect to Fig. $5 \mathrm{c}$, a relatively large variability in precipitation over the windward sides of certain regions (e.g. the Iberian Peninsula, the Apennines and the Balkans) may be explained by features of winter's large-scale flow. Similarity in the wintertime patterns of interannual variability between $\mathrm{P} 0$ and $\mathrm{P} 1$ is confirmed by the high correlation coefficient for EOF1 (0.93), but for EOF2 and EOF3 this coefficient is much lower (Table 5). In JJA, the EOF1 patterns in P0 and P1 are

Table 5. As in Table 4 but for precipitation

\begin{tabular}{|c|c|c|c|c|c|}
\hline Quantity & Source & $\begin{array}{c}\text { EOF } \\
1\end{array}$ & $\begin{array}{c}\text { EOF } \\
2\end{array}$ & $\begin{array}{c}\text { EOF } \\
3\end{array}$ & $\begin{array}{c}\text { Cumu- } \\
\text { lative } \\
\text { variance }\end{array}$ \\
\hline \multicolumn{6}{|l|}{ DJF } \\
\hline Explained variance (\%) & $\begin{array}{l}\text { RegCM } \\
\text { EH5OM }\end{array}$ & $\begin{array}{l}27.8 \\
35.9\end{array}$ & $\begin{array}{l}16.4 \\
15.0\end{array}$ & $\begin{array}{l}11.3 \\
13.3\end{array}$ & $\begin{array}{l}55.5 \\
64.2\end{array}$ \\
\hline Spatial correlation & $\begin{array}{l}\text { RegCM, EH5OM (P1) } \\
\text { RegCM (P0, P1) } \\
\text { EH5OM (P0, P1) }\end{array}$ & $\begin{array}{l}0.86 \\
0.93 \\
0.94\end{array}$ & $\begin{array}{l}0.78 \\
0.28 \\
0.59\end{array}$ & $\begin{array}{l}0.74 \\
0.03 \\
0.39\end{array}$ & \\
\hline \multicolumn{6}{|l|}{ MAM } \\
\hline Explained variance (\%) & $\begin{array}{l}\text { RegCM } \\
\text { EH5OM }\end{array}$ & $\begin{array}{l}21.9 \\
26.9\end{array}$ & $\begin{array}{l}11.4 \\
17.6\end{array}$ & $\begin{array}{r}9.3 \\
11.1\end{array}$ & $\begin{array}{l}42.6 \\
55.6\end{array}$ \\
\hline Spatial correlation & $\begin{array}{l}\text { RegCM, EH5OM (P1) } \\
\text { RegCM (P0, P1) } \\
\text { EH5OM (P0, P1) }\end{array}$ & $\begin{array}{l}0.82 \\
0.95 \\
0.97\end{array}$ & $\begin{array}{l}0.76 \\
0.92 \\
0.97\end{array}$ & $\begin{array}{l}0.83 \\
0.90 \\
0.92\end{array}$ & \\
\hline \multicolumn{6}{|l|}{ JJA } \\
\hline Explained variance (\%) & $\begin{array}{l}\text { RegCM } \\
\text { EH5OM }\end{array}$ & $\begin{array}{l}15.9 \\
18.9\end{array}$ & $\begin{array}{r}9.2 \\
17.7\end{array}$ & $\begin{array}{r}7.5 \\
12.4\end{array}$ & $\begin{array}{l}32.7 \\
49.0\end{array}$ \\
\hline Spatial correlation & $\begin{array}{l}\text { RegCM, EH5OM (P1) } \\
\text { RegCM (P0, P1) } \\
\text { EH5OM (P0, P1) }\end{array}$ & $\begin{array}{l}0.67 \\
0.80 \\
0.88\end{array}$ & $\begin{array}{l}0.40 \\
0.55 \\
0.83\end{array}$ & $\begin{array}{l}0.70 \\
0.62 \\
0.80\end{array}$ & \\
\hline SON & & & & & \\
\hline Explained variance (\%) & $\begin{array}{l}\text { RegCM } \\
\text { EH5OM }\end{array}$ & $\begin{array}{l}20.4 \\
26.0\end{array}$ & $\begin{array}{l}13.9 \\
16.3\end{array}$ & $\begin{array}{l}10.8 \\
13.0\end{array}$ & $\begin{array}{l}45.0 \\
55.3\end{array}$ \\
\hline Spatial correlation & $\begin{array}{l}\text { RegCM, EH5OM (P1) } \\
\text { RegCM (P0, P1) } \\
\text { EH5OM (P0, P1) }\end{array}$ & $\begin{array}{l}0.80 \\
0.05 \\
0.39\end{array}$ & $\begin{array}{l}0.81 \\
0.37 \\
0.81\end{array}$ & $\begin{array}{l}0.83 \\
0.89 \\
0.94\end{array}$ & \\
\hline
\end{tabular}


similar as well (cf. Fig. 5d). A broad correspondence between the EOF1 pattern and mean climate change (Fig. 7c) indicates that the principle year-to-year changes in precipitation occur over the same regions where climate change is relatively large.

\section{SIMULATION AND EFFECTS OF CLIMATE CHANGE ON LOCAL SIGNIFICANT AND EXTREME EVENTS}

Because the effects of many extreme events depend on small-scale physical features related to topographic configuration, regional models appear to be indispensable tools for assessing such occurrences. However, because actual topographic and geographic features may vary within model grid boxes, a direct comparison of model output with observations may be beyond a regional model's design (Rivington et al. 2008). Nevertheless, to gain insight into the potential of RegCM to simulate significant and extreme temperature and precipitation events on small scales, we first compared model climatology for the reference period with data from 20 selected stations in Croatia (Fig. 1c, Table 1). All station data underwent regular checks and quality control at DHMZ. The statistics that are discussed and displayed are given in terms of 'indirect' quantities, i.e. the seasonally averaged number-of-days for a particular threshold of a given parameter. Such estimates indicate not only whether a regional model accurately represents extreme events, but also changes in the frequency of these events.

There are 2 distinct climate regimes in Croatia: continental in the north and central parts and maritime in the south and along the coast. Between these areas, in the narrow mountainous region, the continental regime often exhibits extreme climate conditions. This fact is due to Croatia's complex topography, particularly near the northern Adriatic coast, where a sharp orographic gradient induces large climate differences between the coastal region and inland areas. For example, certain mountain or highaltitude stations are within $10-30 \mathrm{~km}$ from the Adriatic (cf. Fig. 1c). Such a specific topographic configuration makes this region an excellent test for the model, even with a very fine horizontal resolution, to correctly represent climatological data and variations in temperature and precipitation extremes.

We first briefly discuss, without presenting figures, the comparison between the CRU gridded data and the observed data. In all seasons, the CRU T2m matched reasonably well with the observed values in the northern lowlands of Croatia. Along the Adriatic coast, however, the CRU generally underestimates station data, in certain locations by up to $4{ }^{\circ} \mathrm{C}$ in the winter. The observed precipitation is generally represented well by CRU data, and is only slightly underestimated over the mountains in DJF and SON. This comparison indicates that gridded CRU data could be used with confidence for verification purposes over a large portion of Croatia. In the regions with relatively high and steep orography, particularly near the Adriatic coast, there may be, however, difficulties in representing some of the observations.

For the winter threshold T2min $<0^{\circ} \mathrm{C}$ (defined as the cold days), RegCM underestimates the average number of days below the threshold in the continental portion of Croatia. The same is true for the other 'cold' thresholds (T2max $<0^{\circ} \mathrm{C}$ and $\mathrm{T} 2 \mathrm{~min} \leq-10^{\circ} \mathrm{C}$ ), but, for brevity, only the cold days are discussed here. During P0, each station in northern Croatia reported, on average, $>60$ cold days in DJF, whereas the model estimate is $<50 \mathrm{~d}$ (Fig. 8a). The underestimation of cold extremes is indicative of the model's winter warm bias (Fig. 2a). Over the coastal regions, the model generally overestimates the average number of cold days. Between the coast and northern Croatia in the narrow mountainous region, the model correctly represents the tendency toward an increased number of cold days (>50), albeit with a smaller amplitude than is actually observed. The number of cold days for some high-altitude stations located relatively close to the coast clearly deviates from the number predicted by simulations: Zavižan (Stn 11 in Fig. 1c; 82 cold days) is situated above $1500 \mathrm{~m}$, and Gospić (Stn 10; 70 cold days) is at an elevation close to $600 \mathrm{~m}$. Pazin in Istria (Stn 13; 58 cold days) may be considered a climatic exception, as it is located in a valley at approximately $300 \mathrm{~m}$ elevation, and cold outbreaks during the winter can cause low temperatures. These examples illustrate possible difficulties for regional models to accurately represent climatology over a complex terrain. Regardless of the above deficiencies, the model reproduces the contrast between the continental and coastal portions of Croatia reasonably well.

In the near future, the number of cold days in Croatia is expected to decrease with respect to the model's climatology of the reference period by between $10 \%$ in the north and $5 \%$ in the coastal areas (Fig. 8b). This decrease reflects an overall increase in T2min (Fig. 6e), but may also be influenced by the model's systematic error (Fig. 2a). A cautious interpretation of the results shown in Fig. 8b is warranted. 

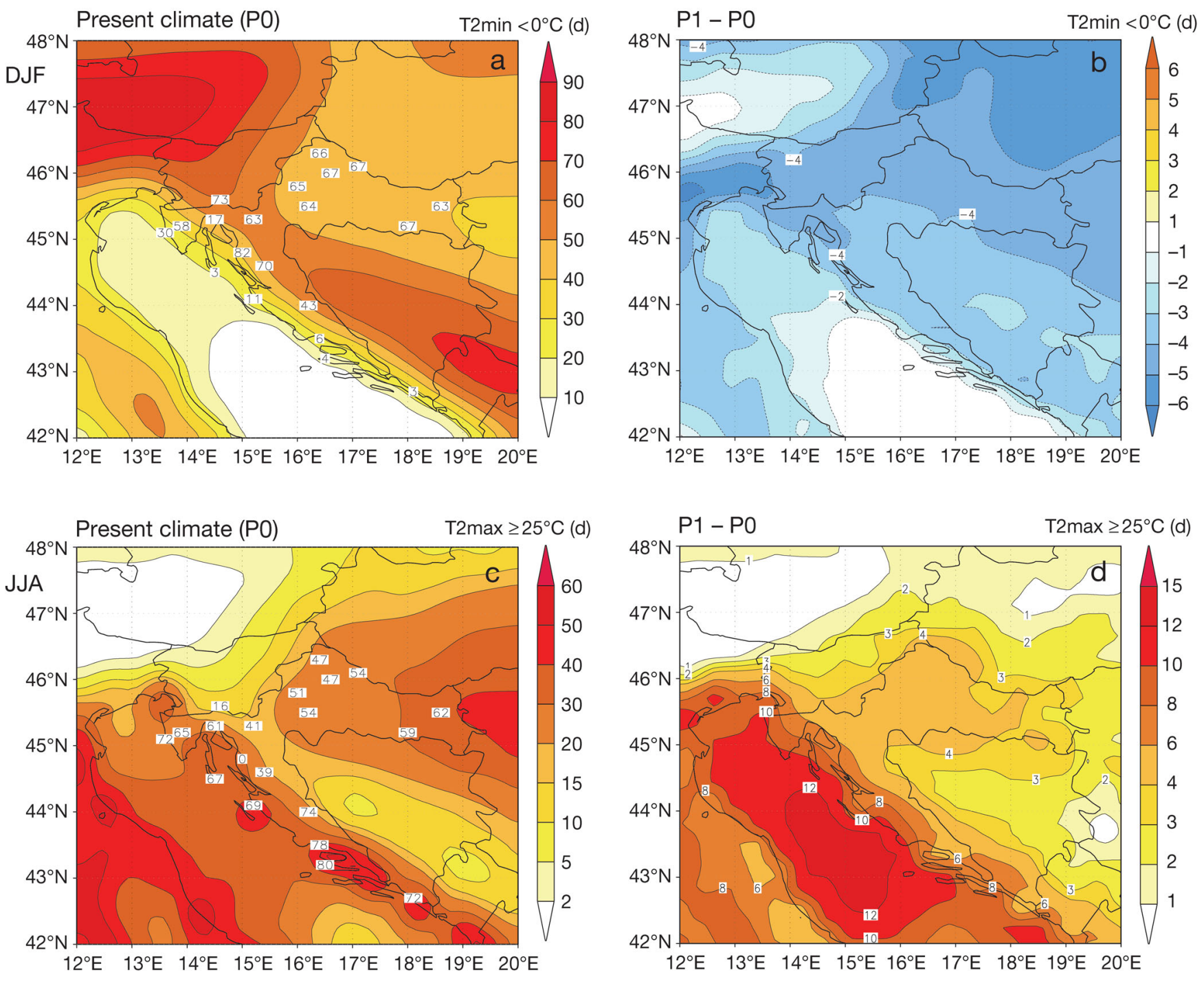

Fig. 8. Mean number of days with DJF T2min $<0^{\circ} \mathrm{C}$ for (a) the reference climate and (b) change P1-P0. Number of days with JJA T2max $\geq 25^{\circ} \mathrm{C}$ for (c) the reference climate and (d) change P1-P0. Numbers in the left panels are number-of-days for station data shown in Fig. 1c. Contours every $10 \mathrm{~d}$ in (a) every $\pm 1 \mathrm{~d}$ in (b), at 2, 5, 10, 15, 20, 30, 40, 50 and $60 \mathrm{~d}$ in (c), and at $1,2,3,4,6,8,10,12$ and $15 \mathrm{~d}$ in (d)

For the summer threshold $\mathrm{T} 2 \mathrm{max} \geq 25^{\circ} \mathrm{C}$ (denoted as the warm days), RegCM again underestimates the average number of days. The same underestimation holds for the threshold $\mathrm{T} 2 \max \geq 30^{\circ} \mathrm{C}$, or hot days; Fig. 8c displays the statistics for warm days only. Over much of the country, the number of warm days predicted by the RegCM is halved in comparison to the observed data. This underestimation can be directly linked to the model's cold bias over the region (Fig. 2c). Generally, the ensemble mean of T2max over Croatia is underestimated from April to October by an average of approximately $2^{\circ} \mathrm{C}$ (not shown), resulting in a reduced number of summer warm and hot days. The minimum number of warm days depicted in Fig. 8c coincides with the mountainous region, indicating that the model tends to represent correctly the spatial distribution of warm temperature extremes in relation to orography. For the data from the 2 stations presented in Fig. 8c, a large discrepancy with modelled values is observed; these stations are the high-altitude Zavižan (Stn 11) and Knin (Stn 18), a station in the Dalmatian hinterland. For the given threshold, it is not appropriate to compare Zavižan (0 warm days) with the model. Even for lower thresholds, the difference of $>1500 \mathrm{~m}$ between Zavižan and the model grid box prohibits the appli- 
cation of lapse rate adjustment (Moberg \& Jones 2004). For the Knin station, 74 warm days were observed, whereas the model predicts this number to be between 20 and 30. This difference is due, not only to model cold bias, but also to a combination of various (near-)surface features related to local physical fields. The station is situated at approximately $230 \mathrm{~m}$ elevation, but, in the model, it is at nearly $500 \mathrm{~m}$. The model's vegetation and land cover for the given location is defined as crop/mixed farming (see the definitions in Elguindi et al. 2007). In reality, Knin is located in a valley surrounded by mountainous rocky outcrops with relatively scarce vegetation, resulting in higher temperatures than are generated in the model. Such a misrepresentation of physical fields may have contributed to a significant local systematic bias in the model (cf. Fig. 2c).

In the near-future climate, the number of warm days is generally projected to increase, ranging from 3 to 4 in northern Croatia to 10 in coastal locations (Fig. 8d), thereby resulting in an approximate increase of between 10 and $15 \%$ relative to the number of warm days in P0 simulations. Because the model substantially underestimates the observed statistics, this increase in the number of warm days appears somewhat unclear; however, according to the data presented in Fig. 6f, the increase of summer high temperatures in P1 will favour an increase in the number of warm and hot days.

To examine extreme precipitation, we chose to determine the number of days when precipitation $\geq 20 \mathrm{~mm}$. In Fig. 9, JJA and SON are shown because different parts of Croatia experience maximum precipitation at different times of the year: northern Croatia in the summer and the Adriatic and mountainous regions in autumn. The number of days with extreme precipitation in JJA is generally underestimated by the model, particularly in the westernmost portion of the country and in the mountainous region (Fig. 9a). This underestimation is primarily due to significant systematic error in these regions (Fig. 4c). Because summer continental rainfall is predominantly convective, the above result may indicate that the model convective scheme is relatively inefficient over mountainous areas. At the central and southern Adriatic coast, the model faithfully represents station data. In the near future, the number of summer days with precipitation $\geq 20 \mathrm{~mm}$ in Croatia will remain nearly unchanged (Fig. 9b).

In $\mathrm{SON}$, the number of days with precipitation $\geq 20 \mathrm{~mm}$ is simulated reasonably well in the northern continental part of Croatia and along the northern and central Adriatic coast (Fig. 9c). The model slightly underestimates extreme precipitation in the mountains, but considerably overestimates it in the south (cf. Fig. 4d). The southern Adriatic coast is well known for its high precipitation in autumn (and winter), which is a time when moist southerly winds from the Mediterranean impinge on the high mountains of the Balkan Peninsula (cf. Fig. 1b,c). Branković et al. (2004) argued that, when the Arakawa-Schubert closure is used within the Grell convection scheme in RegCM (as in our experiments), processes other than convection, e.g. large-scale condensation, may be responsible for such an overabundance of precipitation over elevated regions. In the near future, a weak increase in the number of days for this threshold is observed over eastern continental portions of the country, and a decrease is observed along the coast and inland areas (Fig. 9d), the latter effect being consistent with the reduction in total precipitation indicated in Fig. 7d.

The average number of days with snowfall in DJF is captured reasonably well (Fig. 9e); however, at the high-altitude stations relatively close to the coast, snowfall frequency is generally underestimated. Although the model tends to faithfully represent the maximum number of days with snowfall in the mountains, similar to what was observed for the number of cold days in DJF (cf. Fig. 8a), the complexity of Croatia's terrain and small spatial scales make it quite difficult to correctly represent details of the local observations. In the near-future climate (Fig. 9f), the number of days with snowfall is expected to decrease by 1-2 d over the northern portion of the country, accounting for an approximately $10 \%$ reduction in the northern lowland and an approximately $5 \%$ reduction in the mountainous region. This finding correlates well with the reduction in the number of cold days depicted in Fig. 8b, indicating a strong link between changes in snowrelated metrics and changes in (extreme) temperatures. The low number of days with snowfall in the coastal region will not be reduced in the near-future climate.

The overall winter reduction in snow cover in P1 relative to P0 over southern Europe is almost negligible ( $<1 \mathrm{~mm}$ of water equivalent; not shown). This projection differs substantially from the relatively large change in snow cover reported by Räisänen (2008) based on the global multi-model ensemble forced by the A1B GHGs emission scenario during the years 2000-2049. This discrepancy highlights the need for more high-resolution simulations to reduce modelling uncertainties and to obtain more viable estimates of future climate change. 

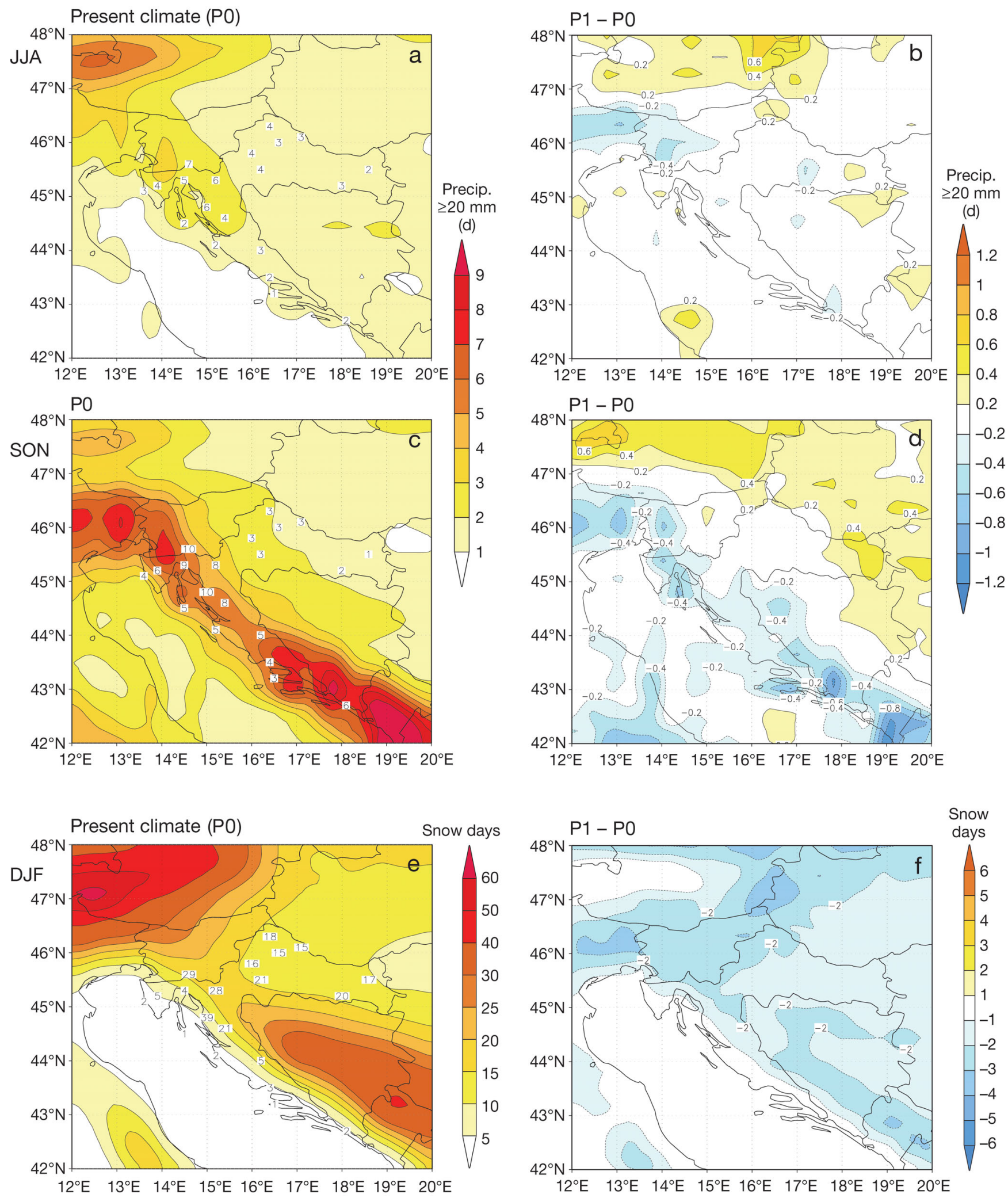

Fig. 9. Mean number of days with precipitation $\geq 20 \mathrm{~mm}$ for (a) the JJA reference climate, (b) JJA change P1-P0, (c) SON reference climate and (d) SON change P1-P0. Number of days with DJF snowfall for (e) the reference climate and (f) change $\mathrm{P} 1-\mathrm{P} 0$. The numbers in the left panels are number-of-days for station data shown in Fig. 1c. Contours every $1 \mathrm{~d}(\mathrm{a}, \mathrm{c})$, every $\pm 0.2 \mathrm{~d}(\mathrm{~b}, \mathrm{~d})$, at $5,10,15,20,25,30,40,50$ and $60 \mathrm{~d}(\mathrm{e})$ and every $\pm 1 \mathrm{~d}$ (f) 


\section{SUMMARY AND CONCLUSIONS}

The regional model RegCM with $35 \mathrm{~km}$ horizontal resolution and 23 vertical levels was employed to downscale the 6-hourly output of the 3-member T63L31 global ECHAM5/MPI-OM (EH5OM) AOGCM ensemble based on the IPCC A2 scenario over the European-Mediterranean domain. The results of dynamical downscaling for the reference period (1961-1990) and the future climate period (20112040) were analysed. For the reference climate, an additional downscaling experiment was performed, whereby RegCM was forced by ERA-40 data (RegCM[ERA40]). This experiment enabled the discrimination of genuine RegCM bias from bias due to the global model. The primary focus of the present study was climate change in the near future, a time period that has been rarely examined in the literature. Such an approach was warranted by the requirements of certain potential users of the information on climate change in Croatia, who face financial planning decisions for the immediate future rather than the second half of this century. It has been demonstrated that, even in the immediate future, statistically significant climate change may be expected, particularly with respect to near-surface temperatures. Compared with the multi-model ensembles, however, the use of only 1 AOGCM results in certain limitations, i.e. our results and conclusions may not extend to other models.

The RegCM results were verified against CRU and EOBS data. With respect to T2m, warm temperatures are reduced in the regional model (cold bias), particularly in the summer, and cold temperatures are increased in the winter (warm bias), particularly in the coldest regions of the domain. In contrast to the cold bias in the summer, which is principally a genuine RegCM error, the warm bias in the winter may be qualified as being equally authentic to RegCM and imported from the boundaries. The RegCM overestimates the precipitation verification data over most of the integration domain in all seasons except JJA. In this season, precipitation is underestimated over southern Europe. Because the positive precipitation bias in the winter over western Europe is reduced in RegCM(ERA40), it can be argued that the errors from lateral boundaries influence the regional model biases; the excessive westerlies from the Atlantic in the global model (cf. Branković et al. 2010) are probably responsible for the overestimation of precipitation observed in the RegCM over western Europe during the winter.
EOF analyses revealed that the observed T2m pattern of interannual variation is best reproduced by RegCM EOF1 in the winter. In the summer, the observed principle pattern of variability may be reproduced in the model by higher modes of variability, i.e. other than EOF1. This finding indicates that, although the contribution to the total variance may be underestimated in certain cases, the model nevertheless effectively reproduces the main pattern of variability observed. RegCM underestimates the observed precipitation variability in nearly all seasons. Interannual variability is primarily influenced by the driving boundary conditions, particularly in the winter.

The regional model response to the increased concentrations of GHGs during the period 2011-2040 generates a strong increase in near-surface temperatures over the European-Mediterranean region. Over southern and central Europe, the amplitude of warming is largest in JJA $\left(+1.8^{\circ} \mathrm{C}\right)$ and smallest in MAM $\left(+0.8^{\circ} \mathrm{C}\right)$. The diurnal amplitude would increase, as well; however, the increase in warm extremes will be larger than the reduction of cold extremes. In terms of precipitation, the projected change (both the increase and the reduction of precipitation) rarely exceeds $1 \mathrm{~mm} \mathrm{~d}^{-1}$. Generally, there is a small degree of spatial coherence among precipitation differences between the future and the reference climates, and, in most seasons, these changes are statistically significant over only a few regions within and adjacent to the Mediterranean. Because of their prevailing weak amplitude, precipitation changes cannot be associated with a single physical effect, such as with changes in MSLP (Giorgi et al. 2004b). Changes in other fields, e.g. soil and atmospheric humidity and sensible heat flux, may also be involved in precipitation changes. The dipolar structure of precipitation changes (i.e. the wetter north and the drier south) that is described in many studies for the late 21st century is not fully established in the immediate future. This fact may have important implications, in that it may require different approaches for adaptations to climate changes in the near future versus those occurring later in the century. Because the climate change signal can be weak in the near future, model systematic errors may impact the results, and near-future climate change data should be carefully interpreted, especially within regions and seasons where errors are relatively high and for which the ensemble spread is large. In contrast to the change in the mean state, the model projects that the spatial pattern of interannual variability in the near future, for both T2m and precipitation, will be largely un- 
changed compared to the patterns of variability in the 20 th century.

The regional model tends to reproduce reasonably well the contrast in the spatial distribution of extreme temperatures, precipitation and snow between the continental and maritime portions of Croatia. However, the frequency of these extremes or significant events, expressed in terms of the 'number of days' for given thresholds, is primarily underestimated when compared with the observations. Because climate extremes are often related to sharp orographic gradients or to complex small-scale orography, the comparison with the Croatian station data indicates that it is difficult for the model to accurately represent the actual climate, even at the $35 \mathrm{~km}$ resolution. Thus, for regions with complex orography, higher climate model horizontal resolutions than were used in our experiments would be desirable. The model systematic errors may have influenced our results, but interannual variability data, which is primarily influenced from the driving global model, is reasonably well simulated in the RegCM. Because the signal-to-noise ratio is generally low in the near-future climate, climate change in terms of the mean and interannual variability is nearly equal in amplitude for some parameters (e.g. precipitation in the summer and snow in the winter). This finding contrasts with projections for the late 21st century, in which the change in the mean is the dominant factor. The observed high consistency between the reduction in the number of days with snowfall and the reduction in $\mathrm{T} 2 \mathrm{~min}<0^{\circ} \mathrm{C}$ implies that changes in snow-related climate metrics in the near future may depend more on changes in extreme temperatures than on changes in precipitation.

Acknowledgements. We acknowledge the World Data Center for Climate (WDCC) in Hamburg, Germany for making the ECHAM5/MPI-OM model data available for downscaling, (via the Climate and Environmental Retrieving and Archive, CERA database). The comments, suggestions and constructive criticism from 4 anonymous reviewers are greatly appreciated. We also thank Zoran Pasaric from the Geophysical Institute, University of Zagreb, for useful discussions. This study was partly supported by the Ministry of Science, Education and Sports of the Republic of Croatia (Project No. 004-1193086-3035).

\section{LITERATURE CITED}

Arakawa A, Schubert WH (1974) Interaction of a cumulus cloud ensemble with the large scale environment. I. J Atmos Sci 31:674-701

Branković Č, Patarčić M, Srnec L (2004) Seasonal dynamical downscaling with ERA-40 data: a sensitivity study. Croat Meteorol J 39:15-39
Branković Č, Srnec L, Patarčić M (2010) An assessment of global and regional climate change based on the EH5OM climate model ensemble. Clim Change 98:21-49

Branstator G, Selten F (2009) 'Modes of variability' and climate change. J Clim 22:2639-2658

Christensen JH, Christensen OB (2007) A summary of the PRUDENCE model projections of changes in European climate by the end of this century. Clim Change 81:7-30

> Christensen JH, Carter TR, Rummukainen M, Amanatidis G (2007a) Evaluating performance and utility of regional climate models: the PRUDENCE project. Clim Change 81:1-6

Christensen JH, Hewitson B, Busuioc A, Chen A and others (2007b) Regional climate projections. In: Climate Change 2007: the physical science basis. Contribution of Working Group I to the Fourth Assessment Report of the Intergovernmental Panel on Climate Change. Cambridge University Press, Cambridge, p 847-940

Déqué M, Jones RG, Wild M, Giorgi F and others (2005) Global high resolution versus limited area model climate change projections over Europe: quantifying confidence level from PRUDENCE results. Clim Dyn 25:653-670

Dickinson RE, Henderson-Sellers A, Kennedy PJ (1993) Biosphere-atmosphere transfer scheme (BATS) Version 1e as coupled to the NCAR Community Climate Model, NCAR Tech. Note NCAR/TN-387+STR, NCAR, Boulder, $\mathrm{CO}$

> Diffenbaugh NS, Ashfaq M (2010) Intensification of hot extremes in the United States. Geophys Res Lett 37: L15701. doi:10.1029/2010GL043888

Elguindi N, Bi X, Giorgi F, Nagarajan B and others (2007) RegCM Version 3.1 user's guide. ICTP, Trieste. Available at: http://users.ictp.it/RegCNET/regcm.pdf

Endler C, Matzarakis A (2010) Analysis of high-resolution simulations for the Black Forest region from a point of view of tourism climatology-a comparison between two regional climate models (REMO and CLM). Theor Appl Climatol 103:427-440

Folland CK, Knight J, Linderholm HW, Fereday D, Ineson S, Hurrell JW (2009) The summer North Atlantic Oscillation: past, present and future. J Clim 22:1082-1103

Früh B, Feldmann H, Panitz HJ, Schädler G, Jacob D, Lorenz P, Keuler K (2010) Determination of precipitation return values in complex terrain and their evaluation. J Clim 23: 2257-2274

Gao X, Pal JS, Giorgi F (2006) Projected changes in mean and extreme precipitation over the Mediterranean region from a high resolution doubled nested RCM simulation. Geophys Res Lett 33:103706. doi:10.1029/2005 GL024954

> Giorgi F (2006) Climate change hot-spots. Geophys Res Lett 33:L08707. doi:10.1029/2006GL025734

> Giorgi F, Bi X, Pal JS (2004a) Mean, interannual variability and trends in a regional climate change experiment over Europe. I. Present-day climate (1961-1990). Clim Dyn 22:733-756

> Giorgi F, Bi X, Pal JS (2004b) Mean, interannual variability and trends in a regional climate change experiment over Europe. II. Climate change scenarios (2071-2100). Clim Dyn 23:839-858

> Grell GA (1993) Prognostic evaluation of assumptions used by cumulus parameterizations. Mon Weather Rev 121: 764-787

Hagemann S, Göttel H, Jacob D, Lorenz P, Roeckner E (2009) Improved regional scale processes reflected in 
projected hydrological changes over large European catchments. Clim Dyn 32:767-781

Hawkins E, Sutton R (2009) The potential to narrow uncertainty in regional climate predictions. Bull Am Meteorol Soc 90:1095-1107

Haylock MR, Hofstra N, Klein Tank AMG, Klok EJ, Jones PD, New M (2008) A European daily high-resolution gridded dataset of surface temperature and precipitation. J Geophys Res 113:D20119. doi:10.1029/2008JD010201

$>$ Hewitt C, Griggs D (2004) Ensembles-based predictions of climate changes and their impacts. EOS Trans Am Geophys Union 85:566

Holtslag AAM, de Bruijn EIF, Pan HL (1990) A high resolution air mass transformation model for short-range weather forecasting. Mon Weather Rev 118:1561-1575

Im ES, Jung IW, Bae DH (2011) The temporal and spatial structures of recent and future trends in extreme indices over Korea from a regional climate projection. Int J Climatol 31:72-86

Jungclaus JH, Keenlyside N, Botzet M, Haak H and others (2006) Ocean circulation and tropical variability in the coupled model ECHAM5/MPI-OM. J Clim 19:3952-3972

Kiehl J, Hack J, Bonan G, Boville B, Breigleb B, Williamson D, Rasch P (1996) Description of the NCAR Community Climate Model (CCM3). NCAR Tech. Note NCAR/TN420+STR, NCAR, Boulder, CO

Kjellström E, Nikulin G, Hansson U, Strandberg G, Ullerstig A (2011) 21st century changes in the European climate: uncertainties derived from an ensemble of regional climate model simulations. Tellus 63A:24-40

Klein Tank AMG, Wijngaard JB, Koennen GP, Boehm R and others (2002) Daily dataset of 20th-century surface air temperature and precipitation series for the European Climate Assessment. Int J Climatol 22:1441-1453

Knutti R (2010) The end of model democracy? Clim Change 102:395-404

Krichak SO, Alpert P, Bassat K, Kunin P (2007) The surface climatology of the eastern Mediterranean region obtained in a three-member ensemble climate change simulation experiment. Adv Geosci 12:67-80

- Lionello P, Boldrin U, Giorgi F (2008) Future changes in cyclone climatology over Europe as inferred from a regional climate simulation. Clim Dyn 30:657-671

Mariotti L, Coppola E, Sylla MB, Giorgi F, Piani C (2011) Regional climate model simulation of projected 21st century climate change over an all-Africa domain: comparison analysis of nested and driving model results. J Geophys Res 116:D15111. doi:10.1029/2010JD015068

Marsland GA, Haak H, Jungclaus JH, Latif M, Röske F (2003) The Max Planck Institute global/sea-ice model with orthogonal curvilinear coordinates. Ocean Model 5:91-127

May W (2008) Potential future changes in the characteristics of daily precipitation in Europe simulated by the HIRLAM regional climate model. Clim Dyn 30:581-603

Meehl GA, Stocker TF, Collins WD, Friedlingstein P and others (2007) Global climate projections. In: Climate Change 2007: the physical science basis. Contribution of Working Group I to the Fourth Assessment Report of the Intergovernmental Panel on Climate Change. Cambridge University Press, Cambridge, p 747-845

> Meehl GA, Tebaldi C, Walton G, Easterling D, McDaniel L (2009) Relative increase of record high maximum temperatures compared to record low minimum temperatures in the U.S. Geophys Res Lett 36:L23701. doi: 10.1029/2009GL040736
Mitchell TD, Jones PD (2005) An improved method of constructing a database of monthly climate observations and associated high-resolution grids. Int $\mathrm{J}$ Climatol 25: 693-712

$>$ Moberg A, Jones PD (2004) Regional climate model simulations of daily maximum and minimum near-surface temperatures across Europe compared with observed station data 1961-1990. Clim Dyn 23:695-715

Nakićenović N, Akamo J, Davis G, de Vries B and others (2000) Special report on emission scenarios. A special report of Working Group III of the IPCC. Cambridge University Press, Cambridge

New M, Lister D, Hulme M, Makin I (2002) A high-resolution data set of surface climate over global land areas. Clim Res 21:1-25

Noguer M, Jones R, Murphy J (1998) Sources of systematic errors in the climatology of a regional climate model over Europe. Clim Dyn 14:691-712

Pal JS, Giorgi F, Bi X, Elguindi N and others (2007) Regional climate modeling for the developing world. The ICTP RegCM3 and RegCNET. Bull Am Meteorol Soc 88: 1395-1409

> Pal JS, Small EE, Elthair EAB (2000) Simulation of regionalscale water and energy budgets: representation of subgrid cloud and precipitation processes within RegCM. J Geophys Res 105:29579-29594

Palmer TN, Doblas-Reyes FJ, Hagedorn R, Weisheimer A (2005) Probabilistic prediction of climate using multimodel ensembles: from basics to applications. Philos Trans R Soc Lond B 360:1991-1998

Park EH, Hong SY, Kang HS (2008) Characteristics of an East-Asian summer monsoon climatology simulated by the RegCM3. Meteorol Atmos Phys 100:139-158

Press WH, Teukolsky SA, Vetterling WT, Flannery BP (1995) Numerical recipes in $\mathrm{C}$ : the art of scientific computing. Cambridge University Press, Cambridge

Räisänen J (2008) Warmer climate: less or more snow? Clim Dyn 30:307-319

Räisänen J, Hansson U, Ullerstig A, Giorgi F and others (2004) European climate in the late twenty-first century: regional simulations with two driving global models and two forcing scenarios. Clim Dyn 22:13-31

$>$ Reichler T, Kim J (2008) How well do coupled models simulate today's climate? Bull Am Meteorol Soc 89:303-311

> Rivington M, Miller D, Matthews KB, Russell G, Bellocchi G, Buchan K (2008) Evaluating regional climate model estimates against site-specific observed data in the UK. Clim Change 88:157-185

Roeckner E, Bäuml G, Bonaventura L, Brokopf R and others (2003) The atmospheric general circulation model ECHAM5. I. model description. Rep. 349, Max-Planck Institute for Meteorology, Hamburg

Roeckner E, Brokopf R, Esch M, Giorgetta M and others (2006) Sensitivity of simulated climate to horizontal and vertical resolution in the ECHAM5 atmosphere model. J Clim 19:3771-3791

Rowell DP (2005) A scenario of European climate change for the late twenty-first century: seasonal means and interannual variability. Clim Dyn 25:837-849

> Rummukainen M (2010) State-of-the-art with regional climate models. Wiley Interdisciplinary Reviews: Climate Change 1:82-96

Szépszó G, Horányi A (2008) Transient simulation of the REMO regional climate model and its evaluation over Hungary. Idöjárás 112:203-231 
Tapiador FJ, Sanchez E (2008) Changes in the European precipitation climatologies as derived by an ensemble of regional models. J Clim 21:2540-2557

Uppala SM, Kållberg PW, Simmsons AJ, Andrae U and others (2005) The ERA-40 re-analysis. Q J R Meteorol Soc 131:2961-3012. doi:10.1256/qj.04.176

van Ulden AP, van Oldenborgh GJ (2006) Large-scale atmospheric circulation biases and changes in global climate model simulations and their importance for climate change in Central Europe. Atmos Chem Phys 6: 863-881

von Storch H, Zwiers FW (1999) Statistical analysis in climate research. Cambridge University Press, Cambridge

Weigel AP, Knutti R, Liniger MA, Appenzeller C (2010) Risks of model weighting in multimodel climate projec-

Submitted: December 15, 2010; Accepted: September 19, 2011 tions. J Clim 23:4175-4191

Willmott CJ, Matsuura K (2001) Terrestrial air temperature and precipitation: monthly and annual time series (19501999) (Version 1.02). Center for Climatic Research, University of Delaware, Newark, DE

Zaninović K, Gajić-Čapka M, Perčec Tadić M, Vučetić M and others (2008) Climate atlas of Croatia 1961-1990, 1971-2000. DHMZ, Zagreb

Zhu J, Liang XZ (2007) Regional climate model simulations of U.S. precipitation and surface air temperature during 1982-2002: interannual variation. J Clim 20:218-232

Zveryaev II (2006) Seasonally varying modes in long-term variability of European precipitation during the 20th century. J Geophys Res 111:D21116. doi:10.1029/2005JD 006821

Proofs received from author(s): February 21, 2012 